\title{
Causes of Low Case Detection and Pulmonary Smear Positive Rates of Tuberculosis in Northern Region of Ghana
}

\author{
Article by Abass Abdul-Karim \\ Zonal Public Health Laboratory, Tamale Teaching Hospital, Tamale - Ghana \\ Email: abass.komei@yahoo.com
}

\begin{abstract}
The study had two main broad but related objectives. The first objective was to determine the actual causes of under detection of pulmonary TB cases in the Northern Region of Ghana. Data was collected through administering a structured questionnaire; and collection of sputum samples from the respondents. The second objective was to determine the actual causes of low smear positive rates by assessing the capacity to effectively perform sputum smear microscopy for Acid Fast Bacilli (AFBs) in the district hospitals where the study was conducted. Collection of data here involved the use of a structured checklist for the laboratory and the staff who performed Tb microscopy. In all, 26 laboratory staff who performed Tb microscopy in the study district hospital laboratories were involved. The study lasted for a period of three months. The study revealed that, $41.2 \%$ of the study participants did not go to hospital when they fell sick. Out of this figure, $20.4 \%$ (21) attributed their inability to do so to poverty, $4.9 \%$ (5) to lack of access, 35.9\% (37) to stigma, 28.2\% (29) to cultural beliefs and 10.6\%(11) attributed it to other reasons.
\end{abstract}

\subsection{Introduction}

Tuberculosis (TB), a disease of antiquity, continues to be a major public health problem worldwide. One-third of the world's over six billion population is infected with the tubercle bacilli with over two million deaths annually [WHO, 2005]. Available data on TB in Ghana indicate that the disease burden is high and TB remains an important cause of major disability and death in the country with a mortality rate as high at about 9 per 100000 [WHO, 2011a]. With a population of over 20 million, the World Health Organization (WHO) estimates 44,041new cases of all forms of TB in Ghana corresponding to a TB incidence rate of 211 per 100,000 inhabitants. Of these cases, 19,285are expected to be smear positive cases [WHO, 2005]. In spite of these figures, The World Health Organization (WHO) estimates that Ghana is detecting only $26 \%$ of all forms of tuberculosis and $36 \%$ of sputum smear positive tuberculosis cases. This is well below the African regional average rate of $47 \%$ and WHO target of $70 \%$. Despite a slight increase of notified tuberculosis cases from 12471 in 2006 to 14,479 in 2008, tuberculosis case detection rate in Ghana has not significantly increased over the years. A comprehensive review of the Ghana National Tuberculosis programme in 2007 and National Tuberculosis Health Sector Strategic Plan for Ghana (2009-2013) clearly identified low TB case detection as one of the main challenges facing TB control in Ghana [WHO, 2011a]. This situation is even much more serious in the Northern Region where the prevalence of tuberculosis is reported to be over eleven percent. Tuberculosis remains a major public health problem in the Ghana with the World Health Organization estimating that Ghana is reporting only twenty six per cent (26\%) of case detection and thirty six per cent (36\%) of smear positive cases [WHO, 2011a]. Even though these statistics are not encouraging for tuberculosis control, equally disturbing is the fact that, the Northern Region is reporting about $10 \%$ and $15 \%$ for both case detection rate and sputum smear positive rates respectively. These figures are far below the national estimates as reported by the World Health Organization. The impact of the disease on the socio-economic situation in the region is quite enormous and gives rise to the interest for this work. 
South American Journal of Public Health

Volume 4, Issue 2, 2016

\subsubsection{History of tuberculosis}

Mycobacterium tuberculosis (MTB) is a pathogenic bacterial species in the genus Mycobacterium and the causative agent of most cases of tuberculosis (TB) [Ryan and Ray, 2004] Consumption, phthisis, scrofula, Pot's disease, and the White Plague are all terms used to refer to tuberculosis throughout history. It is generally accepted that the microorganism originated from other, more primitive organisms of the same genus Mycobacterium. Contrary to previous findings that tuberculosis passed from animals to humans, scientific research has revealed that tuberculosis passed from humans to animals instead. Scientific work investigating the evolutionary origins of the Mycobacterium tuberculosis complex has concluded that the most recent common ancestor of the complex was a human-specific pathogen, which encountered an evolutionary bottleneck leading to diversification[WHO, 2011b]. Analysis of the mycobacterial interspersed repetitive units has allowed dating of this Mycobacterium tuberculosis complex evolutionary bottleneck to approximately 40,000 years ago, which corresponds to the period subsequent to the expansion of Homo sapiens out of Africa. This analysis of mycobacterial interspersed repetitive units also dated the Mycobacterium bovis lineage as dispersing approximately 6,000 years ago, which may be linked to animal domestication and early farming [McClelland, 1909]. Human bones from the Neolithic show a presence of the bacteria although the exact magnitude (incidence and prevalence) is not known before the 19th century. Still, it is estimated that it reached its peak (with regard to the percentage of the population affected) between the end of the 18th century and the end of the 19th century. Over time, the various cultures of the world gave the illness different names: yaksma (India), phthisis (Greek), consumption (Latin) and chakyoncay (Incan), each of which make reference to the "drying" or "consuming" effect of the illness, cachexia. Its high mortality rate among middle-aged adults and the surge of Romanticism, which stressed feeling over reason, caused many to refer to the disease as the "romantic disease."

The term phthisis first appeared in Greek literature around 460 BCE. Hippocrates identified the illness as the most common cause of illness in his time. He stated that it typically affected individuals between 18 and 35 and was nearly always fatal [McClelland, 1909] leading him to forbid physicians from visiting victims of the disease to protect their reputations. Although Aristotle believed that the disease might be contagious [Barnes, 1995], many of his contemporaries believed it to be hereditary. Galen, the most eminent Greek physician after Hippocrates, defined phthisis as the "ulceration of the lungs, thorax or throat, accompanied by a cough, fever, and consumption of the body by pus.

The tuberculosis epidemic in Europe, which probably started in the 17th century and which lasted two hundred years, was known as the Great White Plague. Death by tuberculosis was considered inevitable, being the principal cause of death in 1650. The high population density as well as the poor sanitary conditions that characterized most European and North American cities created a perfect environment for the propagation of the disease.

\subsubsection{Tuberculosis in early civilization}

In 2008, evidence for tuberculosis infection has been discovered in human remains from the Neolithic era dating from 9,000 years ago, in a settlement in the eastern Mediterranean [Daniel, 2004]. This finding was confirmed by morphological and molecular methods; to date it is the oldest evidence of tuberculosis infection in humans. Evidence of the infection in humans was also found in a cemetery near Heidelberg, in the Neolithic bone remains that show evidence of the type of angulation often seen with spinal tuberculosis[Daniel, 2004]. Some authors call tuberculosis the first disease known to mankind.

Signs of the disease have also been found in Egyptian mummies dated between 3000 and 2400 BCE. The most convincing case was found in the mummy of priest Nesperehen, discovered by Grebart in 1881, which featured evidence of spinal tuberculosis with the characteristic psoasabscesses[Daniel, 2004]. Similar features were discovered on other mummies like that of the priest Philoc and throughout the cemeteries of Thebes. It appears likely that Akhenaten and his wife Nefertiti both died from tuberculosis, and evidence indicates 
that hospitals for tuberculosis existed in Egypt as early as 1500 BCE [Dubos and Jean, 1987]. The Ebers papyrus, an important Egyptian medical treatise from around 1550 BCE, describes a pulmonary consumption associated with the cervical lymph nodes. It recommended that it be treated with the surgical lancing of the cyst and the application of a ground mixture of acacia seyal, peas, fruits, animal blood, insect blood, honey and salt. The Old Testament mentions a consumptive illness that would affect the Jewish people if they stray from God. It is listed in the section of curses given before they enter the land of Palestine.

\subsubsection{Ancient asia}

The first references to tuberculosis in Asian civilization are found in the Vedas. The oldest of them [Rigveda, $1500 \mathrm{BCE}$ ] calls the disease yaksma. The Atharvaveda calls it another name: balasa. It is in the Atharvaveda that the first description of scrofula is given. The Sushruta Samhita, written around 600 BCE, recommends that the disease be treated with breast milk, various meats, alcohol and rest [Zink et al., 2003]; and in Chinese literature it appears in a medical text written by Emperor Shennong of China (2700 BCE). The first classical text to mention the disease is Herodotus' Histories in which he relates how the generals of Xerxes abandoned the campaign against the Spartans due to a consumption [Zink et al., 2003].

Hippocrates and many others at the time believed phthisis to be hereditary in nature and in Book 1 of his Of the Epidemics, describes the characteristics of the disease [Chrisman and Kleinman, 1983]. Curiously, one prominent figure that disagreed with the hereditary nature of phthisis was Aristotle, who believed that it was in fact contagious while Galen proposed a series of therapeutic treatments for the disease, including: opium as a sleeping agent and painkiller; bloodletting; a diet of barley water, fish, and fruit. He also described the phyma (tumor) of the lungs, which is thought to correspond to the tubercles that form on the lung as a result of the disease [Hawken et al., 2001]. According to the 13th annual tuberculosis report of the World Health Organization (WHO) - published on World TB Day, March 24, 2009 - there were an estimated 9.27 million new cases of tuberculosis worldwide in 2007 [WHO, 2008a]. Although this figure represents an increase from 9.24 million in 2006, the world population has also grown, making the number of cases per capita a more useful measure of the problem; this figure peaked in 2004 at 142 per 100,000 and fell to 139 per 100,000 in 2007. An estimated 1.32 million people who were not infected with the human immunodeficiency virus (HIV) died of tuberculosis in 2007, as did an estimated 456,000 people who were HIV-positive. Prevalence and mortality rates appear to be falling in all six WHO regions. Thus, the Americas, the eastern Mediterranean, and Southeast Asia appear likely to meet the Millennium Development Goals target, set in conjunction with the Stop TB Partnership and the World Health Assembly, of halving tuberculosis prevalence and tuberculosis-related mortality between 1990 and 2015. This target will probably not be met by the African and European regions [Pitchenik, 1984].

Some 22 high-burden countries collectively account for $80 \%$ of the global tuberculosis burden. In 2007, the countries with the highest prevalence were India (with 2.0 million cases), China (1.3 million), Indonesia $(530,000)$, Nigeria $(460,000)$, and South Africa $(460,000)$; of the estimated 1.37 million cases in HIV-positive persons, $79 \%$ were in Africa and $11 \%$ in Southeast Asia [Curry, 1968]. Disturbingly, there were an estimated 500,000 cases of multidrug-resistant (MDR) tuberculosis in 2007 (including 289,000 new cases); of these, 131,000 were in India, 112,000 in China, 43,000 in Russia, 16,000 in South Africa, and 15,000 in Bangladesh; 55 countries had reported cases of extensively drug-resistant (XDR) tuberculosis by the end of 2008. These last figures are reason for considerable concern and highlight a potential threat to our ability to treat tuberculosis, both in individual patients and in the context of a treatment program [Curry, 1968].

To achieve the target set out in the Global Plan to Stop TB, treatment of 1.4 million cases of MDR or XDR tuberculosis will be required in the 27 countries with the highest burden between 2009 and 2015. The cost of diagnosing and treating these cases was estimated at \$16.9 billion, with annual costs increasing from \$700 million in 2009 to $\$ 4.4$ billion in 2015; the latter figure is 61 times the funding that is available in 2009. In higher-burden regions, the 
South American Journal of Public Health

Volume 4, Issue 2, 2016

proportion of tuberculosis cases that are multidrug-resistant may range from 1 to $14 \%$ or more. Of these cases, the proportions that are extensively drug-resistant may be as high as 21\%. Even in the United States, where the number of MDR cases appears to be declining, the number of XDR cases is increasing. Although countries in Eastern Europe, the former Soviet Union, and China have a large number of MDR cases, reporting suggests that sub-Saharan Africa has a relatively low proportion of drug-resistant cases. However, the incidence of primary drug-resistant cases indicates that these areas may have the highest rates of transmitted MDR tuberculosis in the world [Pitchenik, 1984].

Tuberculosis is a disease of poverty, and the declining incidence in many relatively wealthy areas is not unexpected, but there are other parts of the globe where health systems are defective or simply overwhelmed and cannot cope, because of either a lack of funds and personnel or dysfunctional politics, which lead to the sloppy implementation of directly observed treatment (DOTS) programs and exacerbate the tuberculosis problem. [Pitchenik, 1984]. Resistance to any agent emerges rapidly if there is overt or covert monotherapy or noncompliance. Under less than ideal conditions, isoniazid monoresistance also emerges rapidly. And in the absence of isoniazid, our most powerful bactericidal agent, the risk of resistance to refampicin, the next-most-powerful bactericidal agent, increases, since neither pyrazinamide nor ethambutol (nor streptomycin) is particularly effective in preventing resistance in companion drugs [Pitchenik, 1984]. Once MDR tuberculosis has developed, there is little to stop the rapid acquisition of resistance to the remaining agents. Further progression to pre-XDR and XDR tuberculosis becomes only a question of time. Since this process will take place over some months, or even years, the patient remains infectious, and it is not surprising that transmission of MDR and XDR tuberculosis occurs, particularly in communities with a high incidence of HIV infection (Pitchenik, 1984).

\subsubsection{TB surveillance in ghana}

The Village Volunteer (VV) and Community Clinic Attendant (CCA) concept was introduced in Ghana in 1970 to bring health services to the doorstep of the population. This was to change the over concentration of the health services' resource that was used in tertiary care in the urban towns. The system served only a third of the population and also did not deal with the major causes of morbidity and mortality, which included malaria, diarrhoea and measles, diseases of rural Ghana [Bugri, 2005]. As more Rural Health Posts and Health Centres were being established, the CCAs and VVs were faced out. In the Northern Region where both health facilities and staff were very few, the Guinea Worm Eradication Programme (GWEP) reactivated the VV concept with a new role to facilitate surveillance on the Guinea worm disease. The Community Based Surveillance (CBS) system was piloted in the Northern Region as an expansion of the Village Volunteers surveillance system for the Guinea Worm Eradication Programme. The system was very effective for detecting Guinea worm cases which otherwise would not have come to any health facility since there was no effective treatment for the disease. The health seeking behaviour of the population in general in Ghana was poor; therefore, facility based surveillance only detects a small proportion of cases. The VVs services were expanded to cover other diseases that were easy to recognize and were of priority to the health services. The Northern Region proposed the introduction of the system for a countrywide application. UNICEF recognized the potential of this village based surveillance system and offered to support a nation-wide introduction of the system. Some Regions quickly introduced the strategy, others run into the problem of volunteerism [Bugri, 2005].

\subsubsection{Vaccines}

The first genuine success in immunizing against tuberculosis was developed from attenuated bovine-strain tuberculosis by Albert Calmette and Camille Guérin in 1906. It was called "BCG" (Bacille Calmette-Guérin). The BCG vaccine was first used on humans in 1921 in France [Bonah, 2005] but it was not until after World War II that BCG received widespread acceptance in the United States, Great Britain, and Germany [Comstock, 1994]. 


\subsubsection{Treatments}

As the century progressed, some surgical interventions, including the pneumothorax or plombage technique collapsing an infected lung to "rest" it and allow the lesions to heal-were used to treat tuberculosis [Wolfart, 1990]. Pneumothorax was not a new technique by any means. In 1696, GiorgioBaglivi reported a general improvement in tuberculosis sufferers after they received sword wounds to the chest. F.H. Ramage induced the first successful therapeutic pneumothorax in 1834, and reported subsequently the patient was cured. It was in the 20th century, however, that scientists sought to rigorously investigate the effectiveness of such procedures. In 1939, the British Journal of Tuberculosis published a study by Oli Hjaltested and KjeldTörning on 191 patients undergoing the procedure between 1925 and 1931; in 1951, Roger Mitchellpublished several articles on the therapeutic outcomes of 557 patients treated between 1930 and 1939 at Trudeau Sanatorium in Saranac Lake[Daniel, 1982]. The search for a medicinal cure, however, continued in earnest.

In 1944 Albert Schatz, Elizabeth Bugie, and Selman Waksman isolated Streptomyces griseus or streptomycin, the first antibiotic and first bacterial agent effective against $M$. Tuberculosis[Daniel, 1982]. This discovery is generally considered the beginning of the modern era of tuberculosis, although the true revolution began some years later, in 1952, with the development of Isoniazid, the first oral mycobactericidal drug [Daniel, 1982] advent of Rifampicin in the 1970s hastened recovery times, and significantly reduced the number of tuberculosis cases until the 1980s.

\subsubsection{Current treatment strategies in ghana}

Ghana changed to Fixed Dose Combination (FDC) treatment regime in June 2007. All TB patients in Ghana are expected to be treated at health centres free of charge by taking a combination of specific anti-TB drugs such as isoniazid, rifampicin and ethambutol, and pyrazinamide under supervision for six to eight months to completely kill the TB bacilli. This strategy is called Directly Observed Treatment Short-Course DOTS [WHO, 1998a].

\subsubsection{DOTS strategy}

This comprises five elements for effective TB control. It requires accurate recording and reporting system to provide information for planning and maintaining adequate drug stocks.

\subsubsection{Political commitment}

The first of these elements is a clear and sustained political commitment by national governments is crucial if basic DOTS and the Stop TB Strategy are to be effectively implemented. Political commitment is needed to foster national and international partnerships, which should be linked to long-term strategic action plans prepared by NTPs [WHO, 2008a]. Strategic action plans should address technical and financial requirements and promote accountability for results at all levels of the health system; they should include TB-related and other relevant indicators, and - where appropriate - political commitment should be backed up by national legislation. Local partnerships with many potential contributors will help improve TB care in terms of access, equity and quality [WHO, 2008a].

\subsubsection{Case detection through quality-assured bacteriology}

Bacteriology remains the recommended method of TB case detection, first using sputum smear microscopy and then culture and drug susceptibility testing (DST) as well as strengthened laboratory network involving wide network of properly equipped laboratories with trained personnel necessary to ensure access to quality-assured sputum smear microscopy. This is likely to require additional investments in the laboratory network in many countries. The laboratory network should be based on the following principles of adoption of national standards in accordance with international guidelines; decentralization of diagnostic services, with high proficiency levels maintained; communication among members at various levels of the network; and functioning internal and external quality management, including 
South American Journal of Public Health

Volume 4, Issue 2, 2016

supervision [Shinnick et al., 2005]. Culture and DST services should be introduced, in a phased manner, at appropriate referral levels of the health system. Their functions should include diagnosis of sputum smear-negative TB, diagnosis of TB among HIV-positive adults and children, diagnosis and monitoring of response to treatment of MDR-TB, and testing related to periodic surveys of the prevalence of drug resistance. Maintaining the quality of the laboratory network depends on regular training, supervision and support, and motivation of laboratory staff. Best use should be made of existing public and private laboratories [Shinnick et al., 2005].

\subsubsection{Standardized treatment with supervision and patient support}

The mainstay of TB control is organizing and administering standardized treatment across the country for all adult and paediatric TB cases - sputum smear-positive, smear-negative, and extrapulmonary [WHO, 2007]. In all cases, WHO guidelines on patient categorization and management should be followed. These guidelines emphasize use of the most effective standardized, short-course regimens, and of fixed-dose drug combinations (FDCs) to facilitate adherence to treatment and to reduce the risk of the development of drug resistance. Services for TB care should identify and address factors that may make patients interrupt or stop treatment. Supervised treatment, which may have to include direct observation of therapy (DOT), helps patients to take their drugs regularly and complete treatment, thus achieving cure and preventing the development of drug resistance [WHO, 2006]. Supervision must be carried out in a contextspecific and patient-sensitive manner, and is meant to ensure adherence on the part both of providers (in giving proper care and support) and of patients (in taking regular treatment). Depending on the local conditions, supervision may be undertaken at a health facility, in the workplace, in the community or at home. It should be provided by a treatment partner or treatment supporter who is acceptable to the patient and is trained and supervised by health services. Patient and peer support groups can help to promote adherence to treatment. Selected patient groups, for example prisoners, drug users, and some people with mental health disorders, may need intensive support including locally appropriate measures should be undertaken to identify and address physical, financial, social and cultural barriers - as well as health system - barriers to accessing TB treatment services [WHO, 2008a]. Particular attention should be given to the poorest and most vulnerable population groups. Examples of actions that may be appropriate include expanding treatment outlets in the poorest rural and urban settings, involving providers who practice close to where patients live, ensuring that services are free or heavily subsidized, offering psychological and legal support, addressing gender issues, improving staff attitudes, and undertaking advocacy and communication activities [WHO, 2007].

\subsection{Problem statement}

Available data on TB in Ghana indicate that the disease burden is high and TB remains an important cause of major disability and death in the country [Bass, 1989]. With Ghana's population of over 20 million, the World Health Organization (WHO) estimates 44,041 new cases of all forms of TB in Ghana corresponding to a TB incidence rate of 211 per 100,000 inhabitants. Of these cases 19,285 are expected to be smear positive cases [WHO, 2005]. In spite of the figures above, The World Health Organization (WHO) estimates that Ghana is detecting only $26 \%$ of all forms of tuberculosis and $36 \%$ of sputum smear positive tuberculosis cases. This is well below the African regional average rate of $47 \%$ and WHO target of $70 \%$. Despite a slight increase of notified tuberculosis cases from 12471 in 2006 to 14,479 in 2008, tuberculosis case detection rate in Ghana has not significantly increased over the years [WHO, 2011a]. A comprehensive review of the Ghana National Tuberculosis programme in 2007 and National Tuberculosis Health Sector Strategic Plan for Ghana (2009-2013) clearly identified low TB case detection as one of the main challenges facing TB control in Ghana. This situation is much more serious in the Northern Region where TB case detection and sputum smear positive rates are reported to be about $10 \%$ and $15 \%$ respectively. [RHD, 2011]. These figures 
are far below the national estimates as reported by the World Health Organization in the face of the adverse socio-economic impact of the disease in the Region, and gives rise to the interest for this study.

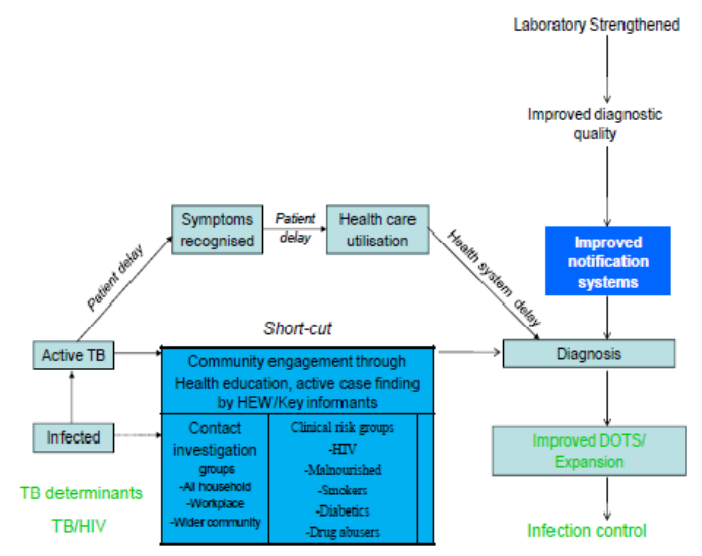

Figure.1 Conceptual framework to improve case detection in Northern Region

(Adapted from WHO; STOP TB Department)

\subsection{General objectives}

To determine the causes of low TB case detection and pulmonary smear positive rates in the Northern Region.

\subsubsection{Specific objectives}

1. To determine the actual causes of low TB case detection.

2. To determine the causes of low pulmonary sputum smear positive rates by assessing the capacity of laboratories in the selected district hospitals in detecting and diagnosing TB cases effectively,

3. To compare the prevalence of pulmonary TB between males and females in the region.

\subsubsection{Study questions}

1. Is the Northern Region recording low pulmonary Tb case detection and sputum smear positive rates?

2. What are the factors causing low Tb case detection rates in the Northern Region?

3. What are the factors causing low pulmonary smear positive rates in the Northern Region?

4. Will the introduction of Health Extension Workers in the communities increase detection of Tb suspects?

\subsection{Justification}

One of the main strategies to control tuberculosis (TB) is to find and treat people with active disease but unfortunately, the case detection rates remain low in many countries. Thus, interventions are needed to find and treat sufficient number of patients to control TB. Several years after its introduction, CBS Volunteerism is grabbling with a lot of problems. The need to move forward is undeniable but given the health seeking behaviour of the general population, the insufficiency of health facilities, poverty and lack of access to health services, there is no likelyhood to detect all cases of targeted diseases occurring in communities through facilitybased surveillance system alone. The need to detect all cases and report is particularly necessary for the control of tuberculosis and possibly, its eradication. Therefore, grass root participation at the community level involving the Health Extension Workers who will be remunerated 
adequately in the form of monthly salaries is necessary for effective disease surveillance system. Ghana's effort of achieving the Millennium Development Goals indicators 23 and 24 by 2015 will be a mirage if efforts are not geared in that direction. To this end, the regions, districts and sub-districts will have to be encouraged to devise means of increasing case detection and treatment under the DOTS strategy. This is one of the reasons which stirred up enthusiasm in conducting this study. The other reason is the negative socio-economic impact of $\mathrm{Tb}$ in the Northern Region. Although there has not been any study on the demographic studies of the disease in the Region, records at the regional health directorate indicate that more males report to health facilities with $\mathrm{Tb}$ than females and since men are mainly the bread winners in this part of the country, families are adversely affected in such circumstances.

\subsection{Literature review}

\subsection{Epidemiology of tuberculosis}

Infectious disease remains the largest cause of illness and death in the world and TB is responsible for the greatest number of deaths among all infectious diseases. It is estimated that the TB bacteria has infected a third of the world's human population and over 2 million people die of TB every year. Most of the illness and deaths due to TB occur in Asia and Africa. In Ghana like other countries in sub-Saharan Africa, TB is a major public health problem and in 2008, 14,479 cases of all forms of the disease were officially reported. The HIV pandemic, overcrowding in our cities and the emergence of antibiotic resistance among the causative agents are contributory factors[WHO, 2005].

\subsection{Royal touch}

With the spread of Christianity, monarchs were seen as religious figures with magical or curative powers. It was believed that Royal Touch, the touch of the sovereign of England or France, could cure diseases due to the divine right of sovereigns. King Henry IV of France usually performed the rite once a week, after taking communion. So common was this practice of royal healing in France, that scrofula became known as the "mal du roi" or the "King's Evil"[Maulitz and Maulitz, 1973]. The monarch (king or queen), sitting upon a canopied throne, touched the afflicted individual, and then presented that individual with a coin - usually an Angel, a gold coin the value of which varied from about 6 shillings to about 10 shillings - by pressing it against the afflicted' neck. Shakespeare's Macbeth describes the procedure quite accurately:

- Strangely visited people

- All swollen and ulcerous, pitiful to the eye

- The mere despair of surgery, he cures,

- Hanging a golden stamp about their necks,

- Put on with holy prayers: and 'tis spoken,

- To the succeeding royalty he leaves

- The healing benediction-Macbeth, Act 4, Scene 3, 171-7

\subsection{Contagion}

Girolamo Fracastoro became the first person to propose, in his work De contagione, that phthisis was transmitted by an invisible virus. Among his assertions were that the virus could survive between two or three years on the clothes of those suffering from the disease and that it was usually transmitted through direct contact or the discharged fluids of the infected, what he called fomes. He noted that phthisis could be contracted without either direct contact or fomes, but was unsure the process by which the disease propagated across distances [Comstock, 1994]

\subsection{Nineteenth century}

It was during this century that tuberculosis was dubbed the White Plague [Comstock, 1994]. Mal de vivir, and mal du siècle. It was seen as a "romantic disease." Suffering from tuberculosis was thought to bestow upon the sufferer heightened sensitivity. The slow progress of the disease 
allowed for a "good death" as sufferers could arrange their affairs [Comstock, 1994]. The disease began to represent spiritual purity and temporal wealth, leading many young, upperclass women to purposefully pale their skin to achieve the consumptive appearance. British poet Lord Byron wrote, "I should like to die from consumption," helping to popularize the disease as the disease of artists. George Sand doted on her pthitic lover, Frédéric Chopin, calling him her "poor melancholy angel" [Daniel, 2004]. In France, a least five novels were published expressing the ideals of tuberculosis: Dumas's La Dame aux camélias, Murger's Scènes de la vie de Bohème, Hugo's Les Misérables, the Goncourt brothers' Madame Gervaisais and GerminieLacerteux, and Rostand's L'Aiglon. Even after medical knowledge of the disease had accumulated, the redemptive-spiritual perspective of the disease continued in literature. (More recently the 2001 film Moulin Rouge is based in part on La traviata, which itself is based on La Dame aux camélias.) [Barnes, 1995].

\subsection{Sanatorium movement}

The advancement of scientific understanding of tuberculosis, and its contagious nature created the need for institutions to house sufferers. The first proposal for a tuberculosis facility was made in paper by George Bodington entitled "An essay on the treatment and cure of pulmonary consumption, on principles natural, rational and successful" in 1840. In this paper, he proposed a dietary, rest, and medical care program for a hospital he planned to found in Maney. Attacks from numerous medical experts, especially articles in The Lancet, disheartened Bodington and he turned to plans for housing the insane [Barnes, 1995]. Around the same time in the United States, in late October and early November 1842, Dr. John Croghan, the owner of Mammoth Cave, brought 15 tuberculosis sufferers into the cave in the hope of curing the disease with the constant temperature and purity of the cave air. Patients were lodged in stone huts, and each was supplied with a black servant to bring meals [Barnes, 1995]. One patient, A. H. P. Anderson, wrote glowing reviews of the cave experience: By late January, early February 1843, two patients were dead and the rest had left. Departing patients died anywhere from three days to three weeks after resurfacing; John Croghan died of tuberculosis at his Louisville residence in 1849.

Hermann Brehmer, a German physician, was convinced that tuberculosis arose from the difficulty of the heart to correctly irrigate the lungs. He therefore proposed that regions well above sea level, where the atmospheric pressure was less, would help the heart function more effectively. With the encouragement of explorer Alexander von Humboldt and his teacher J. L. Schönlein, the first anti-tuberculosis sanatorium was established in 1854, 650 meters above sea level, at Görbersdorf[Barnes, 1995]. Three years later he published his findings in a paper Die chronischeLungenschwindsucht und Tuberkulose der Lunge: IhreUrsache und ihreHeilung. Brehmer and one of his patients, Peter Dettweiler, became proponents for the sanatorium movement, and by 1877, sanatoriums began to spread beyond Germany and throughout Europe. In 1885, Edward L. Trudeau founded Adirondack Cottage Sanitarium, the first tuberculosis sanatorium in the United States, at Saranac Lake, New York[Kopanoff et al., 1988]. Peter Dettweiler went on to found his own sanatorium at Falkensteinin 1877 and in 1886 published findings claiming that 132 of his 1022 patients had been completely cured after staying at his institution. Eventually, sanatoriums began to appear near large cities and at low altitudes, like the Sharon Sanatorium in 1890 near Bost. Sanatoriums were not the only treatment facilities. Specialized tuberculosis clinics began to develop in major metropolitan areas. Sir Robert Philip established the Royal Victoria Dispensary for Consumption in Edinburgh in 1887. Dispensaries acted as special sanatoriums for early tuberculosis cases and were opened to lower income individuals. The use of dispensaries to treat middle and lower-class individuals in major metropolitan areas and the coordination between various levels of health services programs like hospitals, sanatoriums, and tuberculosis colonies became known as the "Edinburgh AntiTuberculosis Scheme [Kopanoff et al., 1988]. 
South American Journal of Public Health

Volume 4, Issue 2, 2016

\subsection{Twentieth century}

At the beginning of the 20th century, tuberculosis was one of the UK's most urgent health problems. A royal commission, entitled The Royal Commission Appointed to Inquire into the Relations of Human and Animal Tuberculosis, was set up in 1901. Its remit was to find out whether tuberculosis in animals and humans was the same disease, and whether animals and humans could infect each other [McCarthy, 2001]. By 1919, the Commission had evolved into the UK's Medical Research Council. In 1902, the International Conference on Tuberculosis convened in Berlin. Among various other acts, the conference proposed the Cross of Lorraine be the international symbol of the fight against tuberculosis. National campaigns spread across Europe and the United States to tamp down on the continued prevalence of tuberculosis. After the establishment in the 1880s that the disease was contagious, TB was made a notifiable disease in Britain; there were campaigns to stop spitting in public places, and the infected poor were pressured to enter sanatoria that resembled prisons; the sanatoria for the middle and upper classes offered excellent care and constant medical attention [McCarthy 2001]. Whatever the purported benefits of fresh air and labor in the sanatoria, even under the best conditions, $50 \%$ of those who entered were dead within five years [McCarthy; 2001].

The promotion of Christmas Seals began in Denmark during 1904 as a way to raise money for tuberculosis programs. It expanded to the United States and Canada in 1907-1908 to help the National Tuberculosis Association (later called the American Lung Association). In the United States, concern about the spread of tuberculosis played a role in the movement to prohibit public spitting except into spittoons[Comstock, 1994]

During the last 100 years in the thousands of years-long history of tuberculosis, we have benefited from unquestioned scientific and clinical progress; but at the same time we have witnessed a global increase in the number of victims and a worsening of the efficacy of control manifested by a rising prevalence of drug resistance in many countries [Daniel, 2004]. Today, tuberculosis is relatively easy to diagnose; when the right combination of medications is made available and taken by the patient, the disease can be cured more than $95 \%$ of the time; and in certain targeted populations, the manifestations of the disease can be attenuated by vaccination and even prevented by chemotherapy. Despite these remarkable achievements, the estimated number of new cases of tuberculosis in the world during each of the last several years has steadily increased: from 8.0 million in 1997 to 8.3 million in 2000, and is expected to reach 10.2 million in 2005 [Styblo, 1989]. There are more people infected with Mycobacterium tuberculosis in the world this year than ever before, and from 1997 through 2000 the number of new cases of tuberculosis and the per capita incidence worldwide rose $1.8 \%$ per year and $0.4 \%$ per year, respectively. Although the overall global tuberculosis situation is deteriorating, it is actually improving in some countries. In the United States, for example, the incidence of newly reported cases of tuberculosis has fallen steadily since 1992 to its lowest level ever, and in 2002 (last report) was 5.2/100,000 population, a stunning public health accomplishment [WHO, 2005] . Such impressive progress, however, is found only in rich (industrialized) nations, although problems remain in many of their marginalized inner-city communities; moreover, the reverse is occurring in many poor (developing) countries, which is where the great majority, $86 \%$, of the world's total population lives. And not only are these destitute regions home to $95 \%$ of all the world's cases of active tuberculosis and $98 \%$ of the nearly 2 million deaths from the disease each year, exactly the same countries are now being ravaged by the pandemic of human immunodeficiency virus (HIV) infection - the most powerful factor ever known to favor the development of tuberculosis [Styblo, 1989]. This historical review examines the century-long paradox of tuberculosis and illustrates an important point made by others [Perkins et al., 2006]. The conquest of tuberculosis by medical advances alone will never occur until the prevailing global inequities of wealth and health care are corrected. Reversing global tuberculosis (TB) incidence by 2015 is one of the Millennium Development Goals [Styblo, 1989]. Prevalence and death rates (indicator 23) and the proportion of cases detected and cured under a directly observed treatment strategy (DOTS) (indicator 24) are used to measure progress towards this goal. For indicator 24, the World Health Organization (WHO) has formulated the following 
goals: a case detection rate of $70 \%$ and a cure rate of $85 \%$. If both targets are achieved, the effect on TB transmission will be considerable [Borgdorff et al., 2000, 1998].

One of the main strategies to control tuberculosis (TB) is to find and treat people with active disease but unfortunately, the case detection rates remain low in many countries. Thus, we need interventions to find and treat sufficient number of patients to control TB [Borgdorff et al., 2000].

\subsection{Spread of TB}

TB is transmitted primarily by tiny airborne particles (droplet nuclei) expelled by a person who has abundant TB bacilli in the lungs through activities such as coughing, sneezing, singing and talking. In addition, aerosols created in the laboratory during smear preparation for staining and culture can spread the TB bacilli. Eating or drinking contaminated animal products especially cattle products such as beef and milk are the main route $M$. bovis (bovine TB) is transmitted to humans. This is one of the reasons why cow milk is pasteurised by heating before drinking (Rieder et al., 1997).

\subsection{Disease formation}

When moist droplets of saliva or mucous containing tubercle bacilli are produced by an infectious person, these droplets travel far and get suspended in the air for several hours. These aerosols of infective particles may be inhaled by another person. If the bacilli establish themselves in the lungs of the person and begin to multiply, then primary infection has occurred. Among those who become infected nearly $90 \%$ never manifest the disease and the bacilli remain dormant within the body. Only in small numbers $-10 \%$ does the primary infection develop into progressive disease. Development of the disease depends on the individual susceptibility. HIV increases the risk of getting TB disease due to lower immune status. Whereas there is $10 \%$ life time risk of TB in HIV negative individuals, there is $10 \%$ annual risk of TB in HIV positive individuals [Kochi, 1991]. Disease signs and symptoms include persistent cough which can productive, sputum production which may be bloodstained (haemoptysis), chest pain, shortness of breath, fever, night sweats, fatigue, weight loss, poor appetite and general feeling of illness (malaise). Although most TB disease affects the lungs (pulmonary), TB can occur in almost any part of the human body as disseminated disease (extra-pulmonary) [Janz and Becker, 1984].

\subsection{Material and methods}

\subsection{Material's used}

- Sputum container (wide mouthed and transparent) was used to collect and store sputum

- A wire loop of internal diameter $3 \mathrm{~mm}$ was used to spread sputum on a microscope slide

- A new and clean slide

- A Diamond pencil was used to put identification number on the slides

- Forceps was used to hold smeared slides over Bunsen burner

- Bunsen burner was used to fix smears on the slides and also used to flame the smears during staining.

- Staining racks were used to arrange slides for staining

- Slide racks were used to dry stained slides

- A binocular microscope was used for microscopy

- Lens tissue and tissue paper, were used for cleaning the objective lens

- Discarding jar containing 5\% phenol served as disinfectant

- Sand bottle was used to disinfect wire loops 
South American Journal of Public Health

Volume 4, Issue 2, 2016

\subsection{Stains and Reagents used for Smear Examination}

(i) $3 \%$ stock Carbolfuchsin stain and $0.3 \%$ working solution.

(ii) $20 \% \mathrm{H}_{2} \mathrm{SO}_{4}$ solution for decolourisation

(iii) $0.3 \%$ methylene blue for counter staining decolourised material in smear

(iv) Tap water for rinsing the smears

(v) Immersion oil (type A) for examination

(vi) Alcohol (> 95\%) for cleaning 100x objective lens

\subsection{Procedures for preparation of stains}

All the stains and reagents were prepared, stored and used according to Standard Operating Procedures (S.O.P's):

3.3.1Fuchsin alcoholic stock solution (3\%) (Solution A)

$30 \mathrm{~g}$ of basic fuchsin powder was weighed into $1000 \mathrm{ml}$ of $95 \%$ alcohol and shook well until powder was completely dissolved in the ethanol. This solution was filtered before staining.

3.3.2Aqueous phenol solution (Solution B) $50 \mathrm{~g}$ of Phenol crystals were heated until liquefied and this was added to $900 \mathrm{ml}$ of distilled water.

3.3.3Working Solution (0.3\% Alcoholic fuchsin) $100 \mathrm{ml}$ of Solution A was added to $900 \mathrm{ml}$ of Solution B.

3.3.4Decolourising agent (20\% aqueous sulfuric acid solution) $200 \mathrm{ml}$ concentrated sulfuric acid was Poured into $1000 \mathrm{ml}$ of distilled water in an Erlenmeyer flask. The concentrated sulfuric acid was poured slowly, allowing it to flow along the side of the flask.

3.3.5Methylene blue counterstaining solution (0.3\%) 3g Methylene blue chloride powder was dissolved in $1000 \mathrm{ml}$ distilled water, mixed thoroughly until the methylene blue powder was completely dissolved.

\subsection{Fixing}

Dried smears were fixed by holding them with forceps and passing them side up over the flame 2-3 times for about 4 seconds each time. The slides were placed on dryer with smeared surface upwards, and air dried for about 30 minutes.

\subsection{Staining}

Fixed slides were placed on the staining rack in serial order, smeared side up, separated by a $1 \mathrm{~cm}$ gap, and never touched one another and were flooded individually with filtered $0.3 \%$ carbolfuchsin working solution. Slides were heated from underneath with the flame of an alcohol soaked cotton swab until vapour starts to rise. The slides were covered with the hot, steaming carbolfuchsin for 5 minutes. The slides were allowed to cool for about 5 minutes, rinsed gently with water to remove excess carbolfuchsin, and excess water tipped to drain off.

\subsection{Decolourizing}

Slides were flooded with the $20 \%$ sulfuric acid solution and allowed to stand for 3 minutes, after which the red colour of carbolfuchsin had almost completely disappeared. Slides were gently washed with water to remove the sulfuric acid and the excess stain; drained off excess rinsing water from slides.

\subsection{Counterstaining}

Covered slides individually with $0.3 \%$ methylene blue counterstaining solution which is the $0.3 \%$ methylene blue and allowed to stand for 1 minute, rinsed slides individually with water, drained water off the slides, which were then allowed to air dry.

\subsection{Ziehl - Neelsen Staining procedure intervals used}

1. Staining for 5 minutes

2. Decolourising for 5 minutes

3. Counterstaining for 1 minute 


\subsection{Microscopy}

A binocular microscope with two objectives, a $40 \mathrm{x}$ magnification objective and an oil immersion $100 \mathrm{x}$ magnification objective and eyepieces of moderate magnification (10x) was used for the examination of the smears. A drop of immersion oil was placed on a dry stained slide to increase the resolving power of the objective. To prevent cross contamination by AFB, the immersion applicators did not touch the slides. Oil immersion in the form of synthetic hydrocarbons and advanced polymers with a refractive index of 1.5, nondrying and non-hardening, with no solvent capability on the smear was used. Acid Fast Bacilli, the bacteria which cause tuberculosis appeared pinkish red in a bluish background as shown in fig A below.

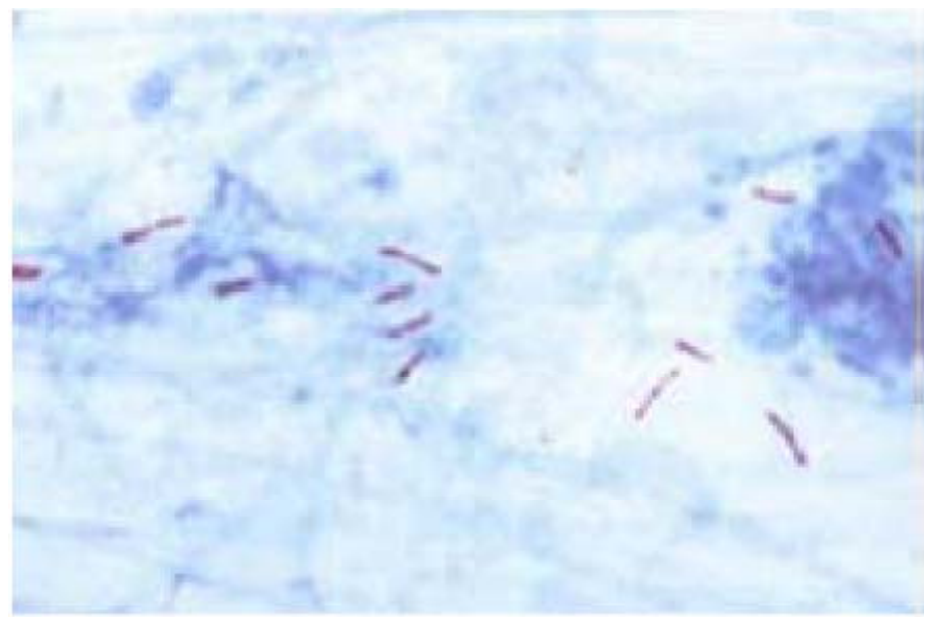

Figure 2: Ziehl-Neelsen staining showing acid-fast bacilli as red rods (AFB Counts Recording/Reporting)

\subsection{World Health Organization/International Union against Tuberculosis and Lung Disease (WHO/IUATLD)}

The WHO/IUALTD grading system was used as shown below (WHO, 2004)

- $\quad$ No AFB in at least 100 fields -negative

- $\quad 1-9$ AFB found in 100 fields- Scanty (exact No)

- 10 to 99 AFB in 100 fields +

- 1 to 10 AFB per fields in at least 50 fields ++

- 10 AFB per field in at least 20 fields+++

\subsection{Study Design}

The study design for this research was cross sectional.

\subsubsection{Study Area}

Profile of region 


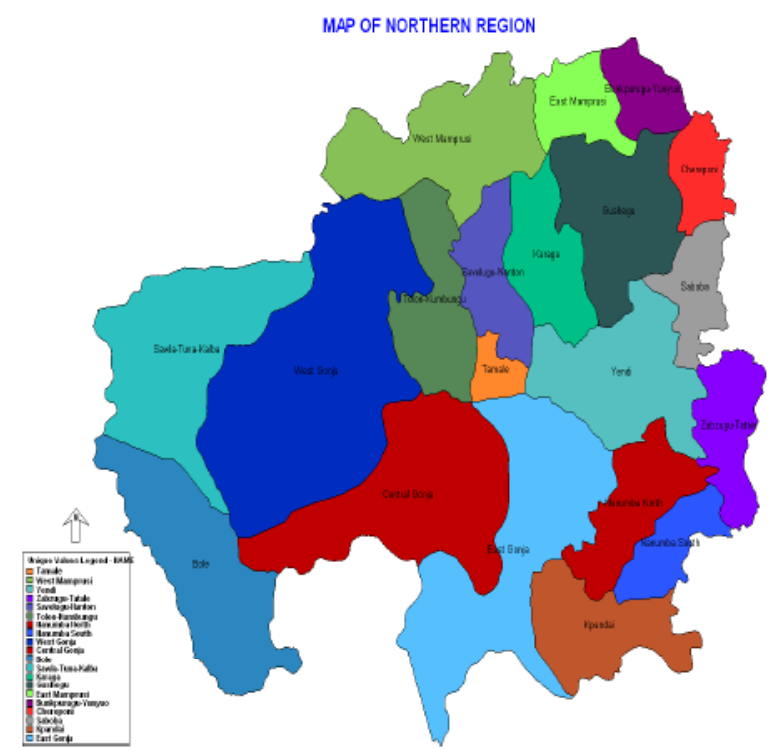

Figure.3: Map of the Northern Region (source: Northern Regional Health Directorate)

The Northern Region is one of the 10 administrative regions of Ghana with a total land area of about 70,384 sq km, about 1/3rd of the land area of the country. It is located between latitude 8:30" and 10:30" North and lies completely in the savannah belt with mainly 2 seasons, the dry and rainy seasons.

\subsubsection{Borders}

It has the Republic of Togo and La Cote D’Lvoire to the East and West respectively as its international neighbours. Further south, the region shares boundaries with the Brong-Ahafo and Volta Regions and to the north, it shares borders with the Upper East and Upper West regions.

\subsubsection{Population characteristics and settlement patterns}

The Northern Region is the least densely populated area of Ghana. The 2010 census projection report gives the regional population as $2,468,557$ with a growth rate of $2.9 \%$. There are 20 districts and between these 20 districts we have a total of 75 sub- districts. In all we have 12 Hospitals, and presently 10 of the hospitals provide TB microcopy. Every TB patient has a treatment supporter who ensures that TB medications and other support are provided for all patients on the TB register. The N/R is divided into 20 political administrative districts. There are 94 Health Sub-Districts, most of which correspond with the local council zones. The population is characteristically distributed in small settlements with population of $200-$ 500 people. There are over 5,000 settlements in the Region, out of which $54.4 \%$ are rural communities with population less than 200 people. The distances between settlements are far apart. This peculiar pattern of distribution of population in the Region has adverse implication for health service delivery, as SDHTs going on out-reach travel over long distances only to reach a small proportion of their target population. A reasonable proportion of the population is in "overseas" areas in 9 of the 20 districts. These are the East Gonja, Kpandai, West Gonja, Central Gonja, West Mamprusi, Nanumba South, Gushegu, Karaga and Tolon/Kumbungu districts. These populations can only be accessed from neighboring regions and or districts or only during the dry season. In the Central Gonja, East Gonja and Kpandai districts, several villages are completely surrounded by the Volta Lake (NRHD; 2012) 


\subsection{Study population}

\subsubsection{Inclusion criteria}

The respondents, fourteen years and above who showed signs suggestive of tuberculosis such as persistent cough, either productive or not productive lasting more than three weeks; fever, weight loss, night sweats, chest pain and/or haemoptysis.

\subsubsection{Exclusion criteria}

Migrant populations e.g. nomadic, known TB clients were excluded and young children below 14 years. Nomadic populations were excluded because their presence in the communities is transient and they can leave these communities at any time; as such their inclusion in intervention programs such as this study will eventually affect long term planning. Young children often times are unable to produce sputum for smear microscopy; hence their exclusion from the study.

\subsection{Sample size}

\subsubsection{Sample size}

A total of Two Hundred and Fourty six respondents were selected using Base sample size formula shown below:

$$
N=\frac{t^{2} \times p(1-p)}{m^{2}}
$$

where:

- $\quad \mathrm{N}=$ required sample size

- $\mathrm{t}=$ =confidence level at $95 \%$ i.e. standard Z-score of 1.96

- $\mathrm{p}=$ estimated prevalence of tuberculosis in northern region (20)

- $\mathrm{m}=$ =margin of error $5 \%$ i.e. alpha $=0.05$

$$
\begin{gathered}
\frac{(1.96)^{2} \times 0.20(1-0.20)}{(0.05)^{2}} \\
\frac{3.8416 \times 0.16}{(0.05)^{2}} \\
0.6146
\end{gathered}
$$

- $\mathrm{N}$ was rounded up to 250 samples.

\subsection{Sampling techniques}

Purposive sampling technique was used. Two Health Extension Workers who were members of these communities were recruited, trained and introduced to the communities. They educated the community members on the need for their involvement in the study in their local languages. Each community selected four key informants who will report Tb suspects to the Health Extension Workers. Structured questionnaires capturing the demographic information, health seeking behavior, barriers to health seeking, marital status educational levels, occupation, ethnicity and geographical location were filled for patients who met the inclusion criteria and were made to produce two sputum samples; one on the spot and the other the following morning. In addition, these Health Extension Workers were in the hospitals to ensure Tb suspects were roped in. Fifty participants were selected and each participant produced two sputum samples giving a total of a hundred samples for each district. For the laboratories, data collection involved the use of a structured checklist capturing information on the physical structure of the lab, human resource of the lab and competency levels of the personnel in $\mathrm{Tb}$ microscopy. 
South American Journal of Public Health

Volume 4, Issue 2, 2016

\subsection{Statistical analysis}

The data collected from the patients and those collected from the laboratories were entered into Epi Info version 7.00 and analyzed.

\subsection{Data collection}

The main tools that were used for the data collection were sputum; after filling a questionnaire from respondents who met the inclusion criteria; and structured checklist for the laboratory.

\subsection{Ethical clearance}

Ethical clearance was sought from the Ghana Health Service through the Northern Regional Health Directorate to carry out the study in the region. This was granted through a letter written by the Directorate and signed by the Regional Director of Health Service seeking permission from the Directors of Health service of the four districts as well as the Tamale Metro Health Directorate.

\subsection{Research limitations}

- The time frame within which this research was carried out was limited as such some areas such as public -private-partnership in Tb case detection and mortality audits on $\mathrm{Tb}$ could not be carried out which in my opinion could have made much impact on the study outcome. It is my hope that future researches would include these areas.

- Unavailability of Purified Protein Derivative (PPD), the kit used for carrying out Manteux test excluded young children below the age of fourteen from the study due to their inability to produce good quality sputum. Future studies in this area should include Manteux test in order to capture children in this age group.

\subsection{Results}

The graph below sums up the various reasons for some of the patients who participated in the study not to attend hospital when they fell sick.

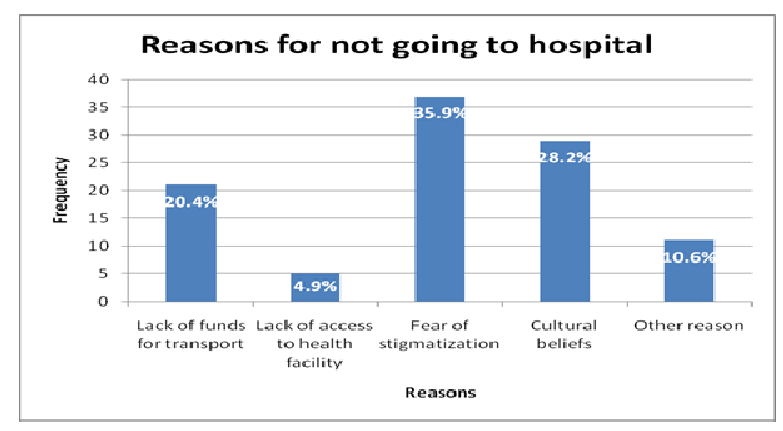

Figure 4: Reasons for some patients not attending hospital (some reasons for under-detection of Tb in the study communities)

Out of the two hundred and fifty respondents who participated in this study, one hundred and three, representing $41.2 \%$ said they did not attend hospital and they attributed this to the following reasons:

\section{- Poverty (Lack of funds for Transport)}

From the study it came up that poverty was a major factor which hindered some patients from hospital attendance; as twenty-one (20.4\%) of them attributed their inability to go to the hospital to poverty. This is in conformity with studies done elsewhere in which it has been established that TB thrives in conditions of poverty and can worsen poverty (WHO, 2005).

\section{- Lack of access to Health Facility}

It was realized from the study (Fig 4.1) that, 5 (4.9\%) of the respondents did not attend hospital due to lack of access to a health facility. This figure may be low comparatively but 
because TB is an infectious disease, these few people could serve as source of infection to other members of their communities. Because of the poor distribution of clinical services especially in the rural, hard to reach communities of Northern Region, and the difficulties that the sick encounter gaining access to and effectively using health services, only a few of new cases are ever diagnosed.

\section{- Fear of Stigmatization}

In this study, thirty-seven (35.9\%) out of the one hundred and three respondents who did not attend hospital cited fear of stigmatization. It was revealed from this study that TB was perceived as a form of curse from the gods when one acted contrary to what was seen as the norm. Due to this fear of being seen in this regard, they preferred hiding their sickness.

\section{- Cultural Beliefs}

Twenty-nine (28.2\%) out of the one hundred and three patients who did not attend hospital attributed it to their cultural beliefs. Their belief, to a large extent was that tuberculosis was a consequence of a curse which could only be reversed by spiritualist rather than seeking intervention through orthodox medical practice. Some thought that seeking cure from the hospital was like hastening ones. Death should the disease be as a result of a curse.

\section{- Other Reasons}

Of the one hundred and three respondents who did not attend hospital to seek medical assistance, eleven (10.6\%) of them attributed other reasons aside those above as being the causes for their inability to attend hospital. These reasons included predominantly using traditional healing methods as some traditional healers in these communities claim to have cure for tuberculosis using herbs.

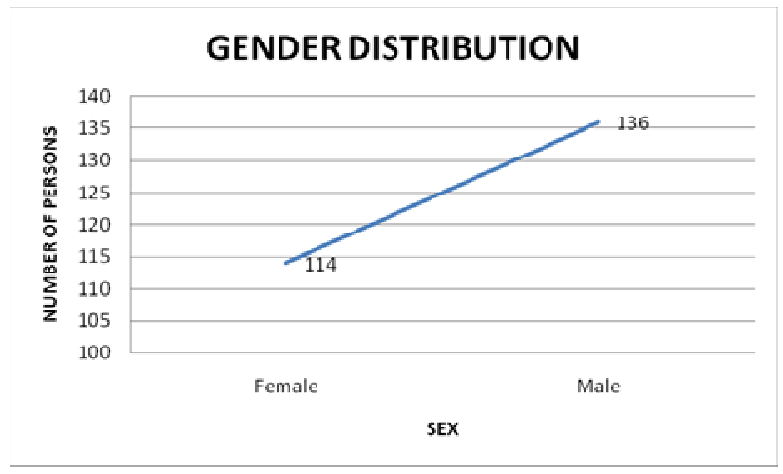

Figure 5: Gender distribution

From the study it was revealed that male respondents were more than female respondents as shown above in Fig 4.2. The male to female ratio being 1:2. This confirms many studies that have been conducted across the world in this area of research;

\subsection{Educational level of participants}

From the frequency distribution of education (Fig.4.13 below), it could be seen that, respondents without formal education were in the majority; they comprised 84(33.6\%) followed by those with junior high school education 56 (22.4\%), then tertiary education 43(17.2\%), primary school education 34(13.6\%) and those with senior high education 33(13.2\%). 
South American Journal of Public Health

Volume 4, Issue 2, 2016

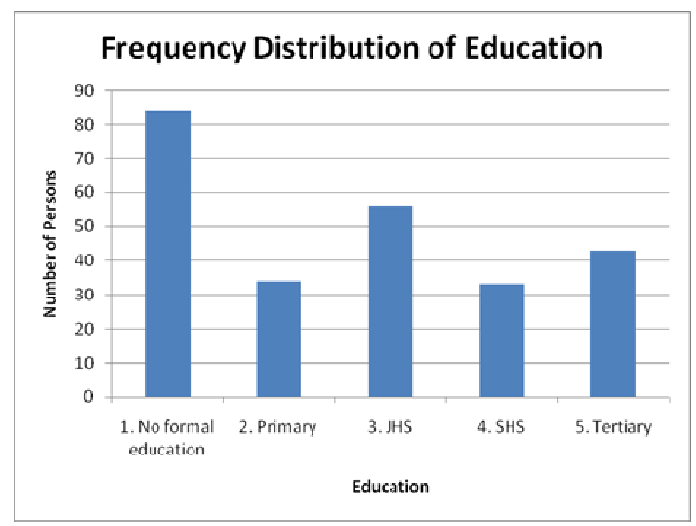

Figure.1: Respondents educational level

\subsection{Occupation of respondents versus TB status}

Respondents were sampled from twenty professional groups and as can be seen from the occupation distribution graphs (Fig 4.14) farmers were the majority of the participants; being ninety (36\%) out of the total two hundred and fifty sampled. Teachers follow with 36(14.4), Students -26 (10.4\%), traders -41 (16.4\%), drivers-13 (5.2\%), health staff-7(2.8\%), Seamstress7(2.8), housewife -6(2.4\%), Banker-4(1.6\%), Unemployed-4(1.6\%), Mechanic-3(1.2\%), Mason-3(1.2\%), Acconutant-2(0.8\%), Hairdresser-2(0.6\%) Truckpusher, fishing, Herbalist, Galamsey operator, retired security personnel as well as security services contributing one each. In all, 103(41.2\%) participants' sputum samples were confirmed by the sputum smear microscopy as being positive for Acid Fast Bacilli. Out of this figure, farmers contributed 44 (42.7\%) followed by traders 41 (20.4\%), teachers 15 (14.6\%), students $11(10.7 \%)$, health staff 7(6.8\%), unemployed 4 (3.9\%), Driver, Hair dresser and seamstress 2 (1.9\%) each, and Truckpusher, Mechanic House wife and Herbalist contributing 1 (0.0097\%) each.

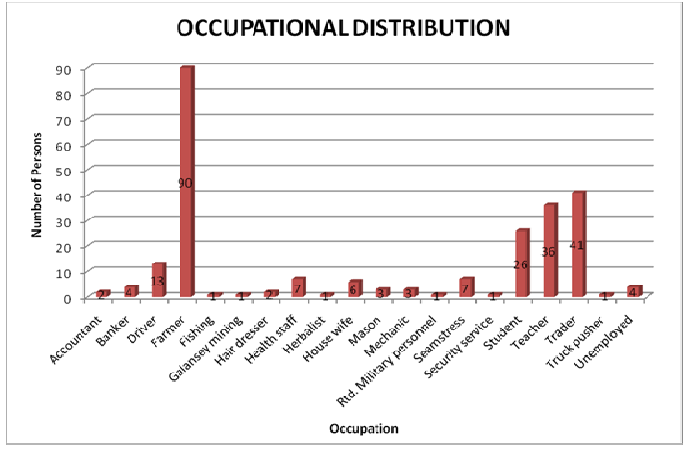

Figure.7: Occupational distribution of respondents

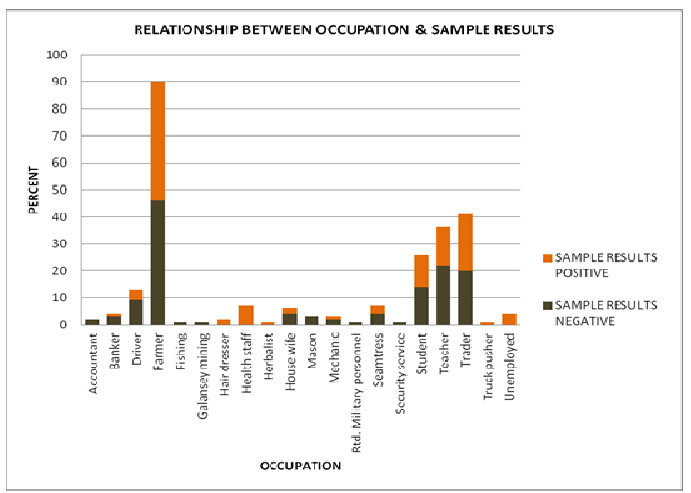

Figure 8: Occupation vs Tb status 


\subsection{Results from laboratory checklist}

Laboratories of the health facilities in the study area were assessed on their capacity to do effective microscopy of mycobacterium tuberculosis based on a checklist designed for this study. It comprised parts labeled A-E. Part A dealt with the physical structure of the laboratory. The results are given in Table 1 below.

\subsection{Physical structure of laboratory}

From Table 4.1, below, it is seen that, $80 \%$ of the facilities had adequate ventilation, all the facilities had their laboratory unit separated from other areas, $60 \%$ of the laboratories were restricted to authorized persons in terms of access and $80 \%$ of the laboratories had the bench for sputum smear preparation separated from other work benches. The physical structure of the laboratory in all cases was good from the above analysis.

Table. 1: Physical structure of the laboratory

\begin{tabular}{|l|l|l|}
\hline Adequate ventilation & Frequency & Percent \\
\hline No & 1 & $20.00 \%$ \\
\hline Yes & 4 & $80.00 \%$ \\
\hline Total & 5 & $100.00 \%$ \\
\hline $\begin{array}{l}\text { Laboratory separated from } \\
\text { other areas }\end{array}$ & Frequency & Percent \\
\hline Yes & 5 & $100.00 \%$ \\
\hline Total & 5 & $100.00 \%$ \\
\hline $\begin{array}{l}\text { Access to the laboratory } \\
\text { restricted to authorized } \\
\text { persons }\end{array}$ & Frequency & Percent \\
\hline No & 2 & $40.00 \%$ \\
\hline Yes & 3 & $60.00 \%$ \\
\hline Total & 5 & $100.00 \%$ \\
\hline $\begin{array}{l}\text { The bench for smear } \\
\text { preparation separated from } \\
\text { other work benches in the lab }\end{array}$ & Frequency & Percent \\
\hline No & 1 & $20.00 \%$ \\
\hline Yes & 4 & $80.00 \%$ \\
\hline Total & 5 & $100.00 \%$ \\
\hline
\end{tabular}

Part B comprised category of staff i.e. human resource and competency assessment of these staff. The results are shown in Table 2 below:

\subsection{Human resource}

\subsubsection{Laboratory staff strength}

It could be seen from the table above that, apart from the Tamale teaching hospital, the rest of the facilities lacked adequate personnel resulting in situation where untrained personnel perform tuberculosis microscopy. Even in the situation where there are adequate numbers of staff such as was the situation with the teaching hospital, they may either be newly recruited and might lack the requisite skill for effective microcopy, or they could be old staff who are not motivated enough to do same. This situation will contribute to increased false negative results as it is the current situation in the northern region. 
South American Journal of Public Health

Volume 4, Issue 2, 2016

\subsubsection{Competency assessment of lab staff}

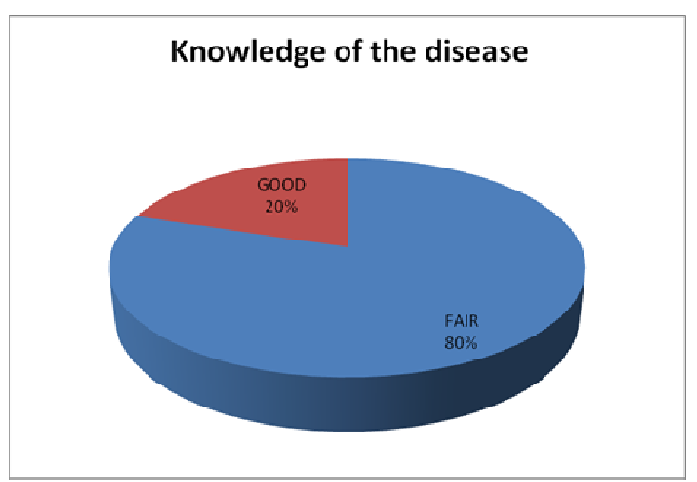

Figure. 9: Knowledge of TB disease by laboratory staff

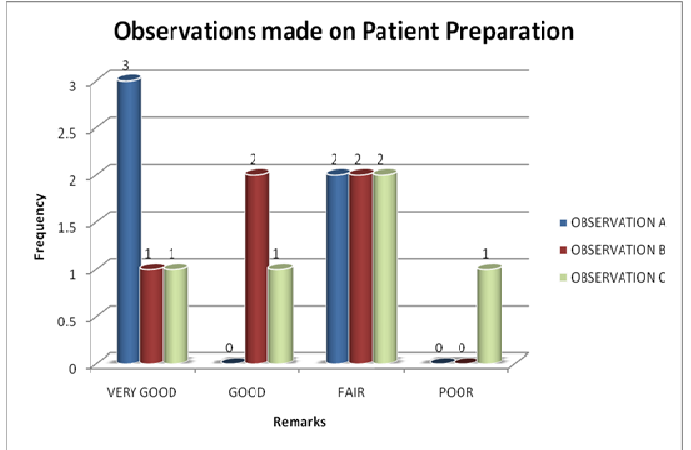

Figure. 10: Observation made on patient preparation

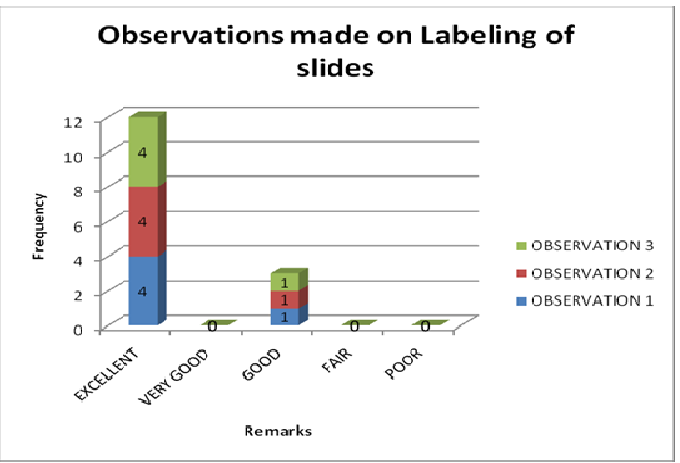

Figure. 11: Observation made on labelling of slides

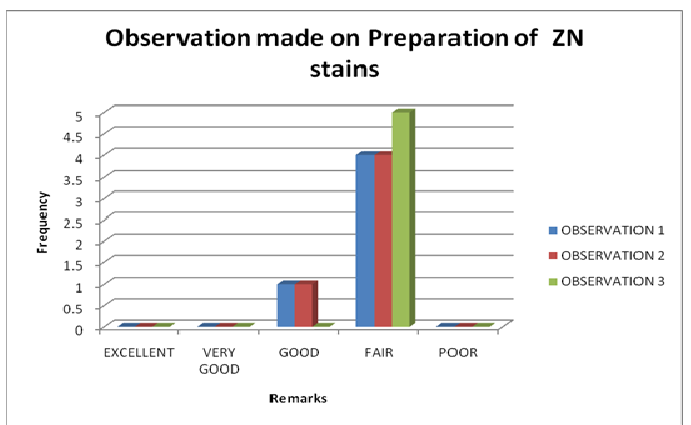

Figure.12: Observation made on preparation of ZN stains 


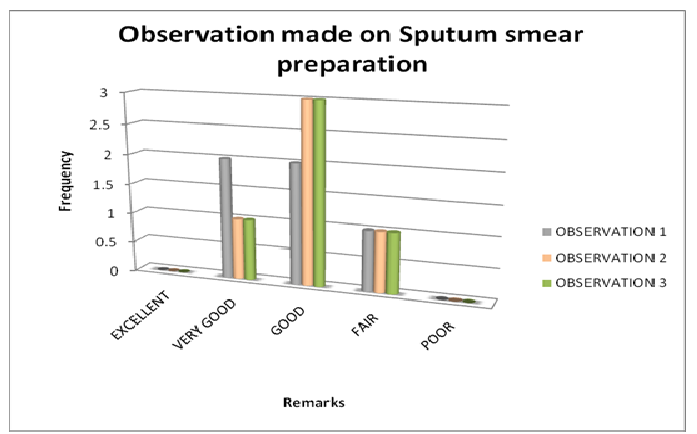

Figure. 13: Observation made on sputum smear preparation

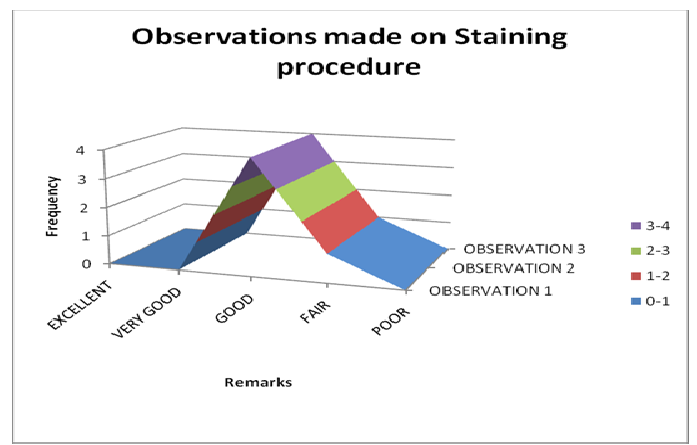

Figure. 14: Observation made on staining procedure

\subsection{Assessment on TB microscopy}

Three participants in observation A had a very good mark for microscopy and two participants had fair. In obsevation B, there were five participants with one of them having a very good grade, two having a good grade and the other two having a fair grade. I $\mathrm{n}$ observation $\mathrm{C}$, there were five participants with one having a very good grade, one good grade, two fair and one poor. Those with the fair and poor grades arethe gray areas in Tb microscopy leading to false negatives.

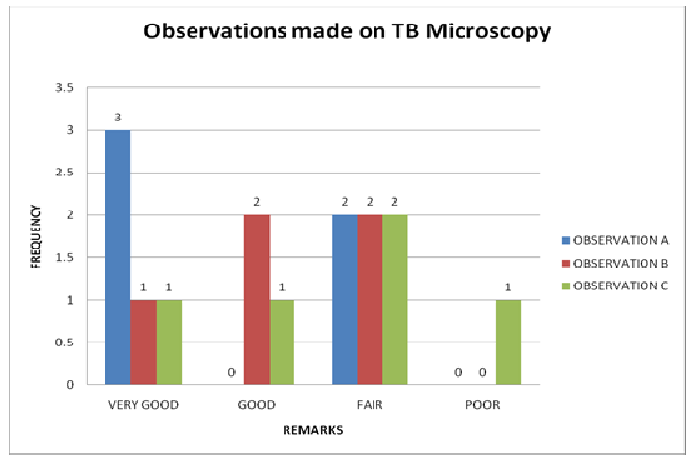

Figure. 15: Observations made on TB microscopy 
South American Journal of Public Health

Volume 4, Issue 2, 2016

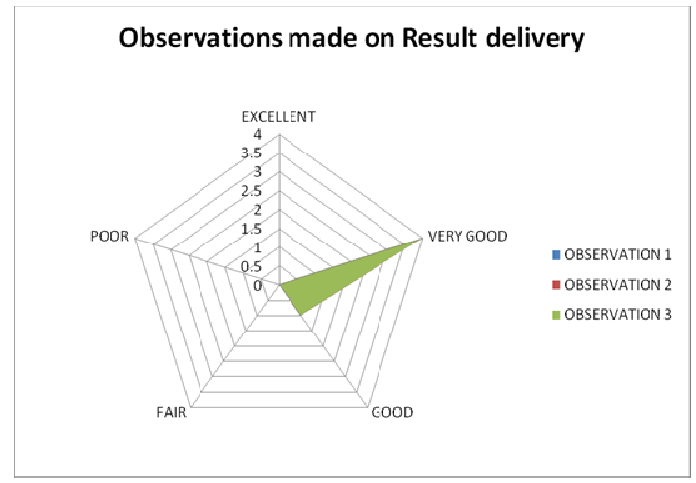

Figure. 16: Observation made on result delivery

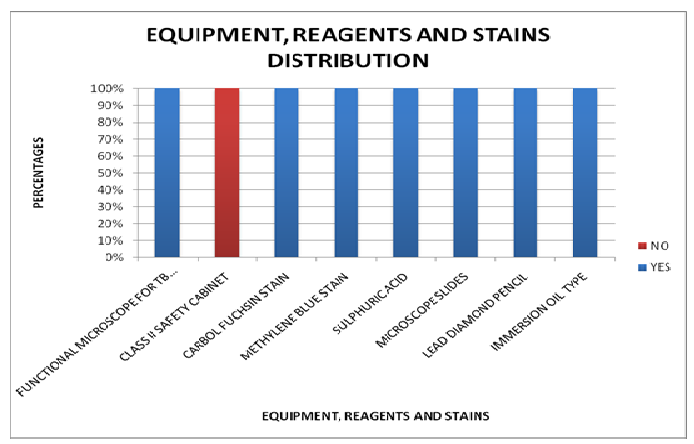

Figure. 17: Equipment, Reagents and Supplies

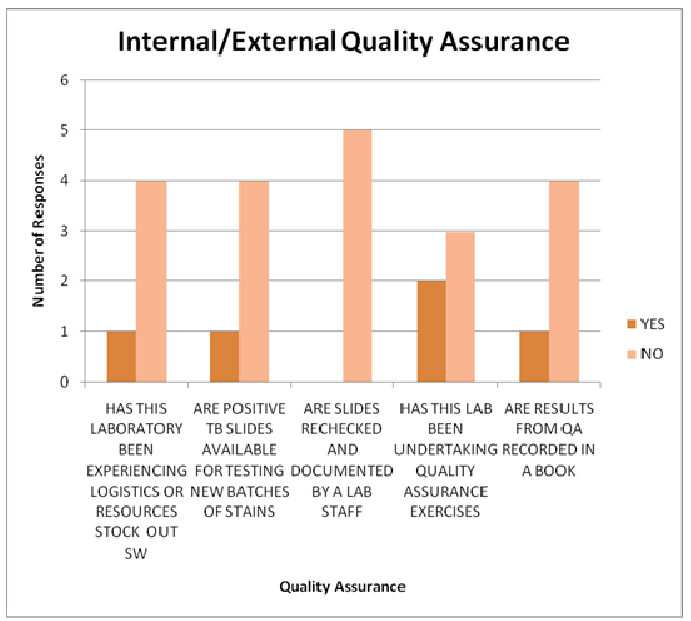

Figure. 18: Internal/External Quality Assurance

As can be seen from Fig 4.12 the study revealed that $90 \%$ of the facilities did not experience logistics or resources stockouts within the last three months preceding the study which could have prevented TB microscopy in the facilities. Also, $90 \%$ of these facilities did not store slides for testing new batches of stain. In all the facilities slides were not rechecked by the laboratory supervisor after initial observation to corroborate and document results. Again, $40 \%$ of the laboratories were not involved in any form of external assurance programs. Those facilities which were involved in eternal quality assurance did not have records on them.

\subsection{Discussion}

Comparing appendices, A and B to table C, it could be seen that before the interventions, percentage monthly average positive for the districts was $8.3 \%$ but after these interventions it 
moved up to 33\% showing that there was a significant increase of tuberculosis suspects who were identified and confirmed within the intervention period. Stigma against Tb patients was top among the barriers to seek medical intervention followed by cultural beliefs, poverty, other reasons and lack of access to health facility in that order. With this trend, there will be the need for maximum effort to be able to break through especially the cultural barrier as well as those of stigma and others.

There is a long history of documented linkages (mainly from Europe and the United States) between TB and poverty at societal, community and patient levels. Although confirming that documentation on linkages between TB and poverty in low-income countries is far from comprehensive, the fundamental conclusion from these reviews is that, "while TB is not exclusively a disease of the poor, the association between poverty and TB is well established and widespread"(WHO, 2005). Throughout the world, poor people and those from disadvantaged social groups suffer more illness and die sooner than the more privileged. Poor and socially excluded people face greater exposure to many health threats, and when they fall sick they are much less likely to receive adequate care. Social factors including the effects of poverty account for the bulk of the global burden of disease and death and for the largest share of health inequalities between and within countries. In high income countries, the average estimated incidence of tuberculosis (TB) is 10/100 000; in low-income countries it is 20 times higher (WHO, 2005). TB is much more common in poor communities because overcrowding is common - people are likely to live in dark, unventilated rooms, and thus more likely to be infected by TB and to receive large doses of the bacilli. Patients' resistance to the disease is reduced, particularly by malnutrition and other diseases such as HIV. TB makes patient and family poorer because the patient will probably be unable to work Patients in remote areas may not be aware of or able to access free treatment and may end up paying more than they can afford to traditional healers or doctors who are not experts in TB. Where treatment and drugs are free there is often a cost of travelling to clinics, both to collect drugs or to have each dose supervised.

Studies suggest on average patients lose 3-4 months of work time. The annual loss is equivalent to loss of $20-30 \%$ of the family household income. If a patient dies the family loses about 15 years of income. The presence of a TB patient in a household entails major reallocation of time and resources towards care of the patient, and away from work. If wife develops TB it is not uncommon for the husband to leave her. For female members of the family the stigma attaching to TB may prevent marriage (WHO, 2005).

The family may sell assets because of reduced income - pushing them further into poverty and losing their future potential for earning. The family may end up begging. Patients and their families may stop using water from the public tap because it costs too much - and go back to using open water sources. WHO's commitment to the promotion of equity and pro-poor policies in its disease prevention and control activities is based on the recognition of poverty as a major barrier to health and health care. In the case of tuberculosis (TB), the links between poverty and disease burden have been documented for many years. This document addresses the integration of national TB control programmes on the practical issues involved and options for action. The following six principal steps are recommended and described in the document (Mata, 1985). Payments for transport to and from health facilities for patients and their caregiver(s) for several different visits make up a large proportion of costs before diagnosis is established. If treatment requires frequent travel (e.g. for observation of treatment), then these transport costs may continue to accumulate after diagnosis, even if the distances travelled are not very great. The time lost in repeat visits to health providers is also costly in various ways, for instance through opportunity costs including lost earnings, neglected household responsibilities and lost productivity. Overall, therefore, costs to patients can easily accumulate even when diagnostic tests and drugs for TB treatment are provided free of charge. Although aggregate costs for poor people tend to be lower in real terms than costs for other social groups, costs relative to annual or monthly income are much higher for poor people than for others. In the example illustrated in 
South American Journal of Public Health

Volume 4, Issue 2, 2016

Table 1 the poor spend less on diagnosis than the non-poor but the overall costs faced by the poor are extremely high relative to their incomes (WHO, 2005).

Cultural barriers may be difficult to overcome but promotion of community mobilization, ensuring that staff attitudes do not reinforce stigma, advocacy for worker protection to avoid loss of work as a result of TB, ensuring that the TB health promotion plan takes account of poor and vulnerable groups and exploring possibilities for referral mechanisms from traditional health-care providers to the health centres may gradually overcome the cultural and stigma barriers. Poverty might be reduced if these barriers are overcome in that the study revealed that 90 out of the total respondents of 250 were farmers and out of this, 44(48.9\%) had TB; this translates to $37.6 \%$ of total TB cases. Also, 103 out of the 205 respondents did not attend hospital and this figure comprised 90(87.4\%) farmers. The involvement of Health Extension Workers in sputum collection and treatment improved smear-positive case detection and those confirmed as being positive were roped into care under DOT. This meant health care was brought possibly closer within access of clients. This could be applied in settings with low health service coverage such as rural northern region and in countries where there is shortage of health workers such as Ghana.

Ideally, laboratories are suppose to prepare slides for quality control purposes but non of the laboratories did so. The laboratory registers in all the facilities were not properly and completely registered. Also there were inadequate patient addresses, results of some patients not entered in the register and months of follow-up not indicated. Indeed the study revealed that both quality control and quality assurance were major deficincies which led to many false negatives in the laboratories contributing to the overall low numbers of case identification and low aputum smear positive cases recorded over the years in the region.

Inadequate number of qualified personnel working in the laboratories was another major factor identified. Numbers of clients to the laboratories have been increasing with the introduction of the National Health Insurance scheme and this had led to an increase in the turnaround time for laboratory investigations. With this increase in the volume of work, Tb suspects were those most affected because there was no motivation in that direction and so the sputum samples were kept till the volume of work was very minimal before they were worked on or in some situations the laboratory staff worked on them after close of work in the evening. This means they worked on them under dures and stress. This resulted in some of the weak positives(+) being reported as negative. Modification of schedules for $\mathrm{Tb}$ diagnostic and treatment services to meet local needs; developing the communication skills of staff; discouraging staff from discriminating against poor patients; using total quality management to ensure that services remain responsive to the needs of the poor; engaging in health service decentralization to promote capacity strengthening at the periphery and inclusion of $\mathrm{Tb}$ control as a district-level priority.

Encouraging public-private mix for DOTS initiatives in the form of a policy, provision of TB diagnosis and treatment in the workplace; extension of Tb microscopy services to poor communities, provision of diagnosis and discouragement of unofficial charges to patients may all go a long way to encourage the poor to attend hospital. Although from this study lack of access to health facility contributed only $4.9 \%$ of the reasons for not attending hospital, this could be overcome by extension of diagnostic and treatment services to remote, poor communities; bringing patients from remote areas to Tb service centres and development of a community-based $\mathrm{Tb}$ care model.

From the above analysis it can safely be said that if cultural and stigma barriers are overcome, most rural people will seek medical intervention at healthcentres or hospitals whenever they fall sick and this will keep them healthy and productive by working to break through the poverty barrier. Also, if these challenges are addressed and sustained, staff attitude towards $\mathrm{Tb}$ microscopy will improve and this ultimately will significantly contribute to $\mathrm{Tb}$ control in the region.

In order to effectively control $\mathrm{TB}$, there is the need for collaboration on the part of the government with private health service providers. This however is a huge challenge in the 
region in the sense that, there is no single private health provider in the region which provides service to Tb clients. In the first place, there are only a few private health service providers in Tamale, the regional capital and none, at all in the catchment areas of the districts selected for this research and due to that public -private partnership will be a challenge in these areas. Most high-resource countries have large private health-care systems, including laboratories, which provide high-quality care and services. Although the quality of care correlates with resources, factors such as laboratory quality standards and regulations, mandatory reporting of cases of TB and other infectious diseases, and specific public initiatives to work with private providers have also been responsible for successful integration of disease control programmes with private health care (Kusznierz et al., 2004; Shinnick et al., 2005).

In Ghana there is the need to encourage private sector participation in TB case detection because according to Tuberculosis Assistance Program for Ghana (2007-2010), out of 601 medical laboratories (both public and private) existing in 2007, only 211(35\%) were providing sputum smear microscopy and this could be built upon by way of motivation especially to the private operators. Since TB microscopy is free, private service providers may not want to venture into it but if they are provided with support in the form of chemistry and haematology reagents for their services, it will lure them into coming on board. Strict monitoring must be instituted thereafter to assure the quality of testing and reporting in the private laboratory sector. Also the National TB program must develop strategies to enroll these private laboratories in EQA programmes and require reporting and referral of TB cases.

As seen in Fig 4.12 about $90 \%$ of the activities listed under quality assurance were not adhered to by the laboratories. This is in sharp contrast to what pertains in the developed countries which have taken advantage of new technologies that provide rapid detection,

\subsection{Conclusion and recommendations}

This study showed that, two reasons; (1) Poor health seeking behavior as a result of poverty, lack of access to health facilities, fear of stigmatization, cultural beliefs and other factors on the part of the people and (2) Lack of capacity on the part of the laboratories to diagnose TB through effective microcopy.

\subsection{Recommendations}

1. Laboratories play a pivotal role in performing research, especially operational research that supports evidence-based decisions for guiding laboratory practice, it is recommended that, whenever possible, such research should be performed in the district hospital laboratories. Research carried out to improve diagnostic methods and techniques can be published in the literature and guide Ghana's decisions about implementing changes in technology and procedures. The zonal Public health laboratory in Tamale has the capacity to perform operational research, and must be encouraged in the form of training in research methods, and by developing partnerships with research-focused institutions such as universities to carry these out. It is important however, that such encouragement if offered, the zonal public health laboratory balances research activities with priority initiatives to monitor and support the laboratory network. This will serve as an incentive to the staff who in turn will give off their best to support Tb control in Northern Region.

2. There is the need for an intensive and sustained education in the Region about TB, its etiology, symptoms and mode of transmission since from the study, $24 \%$ and $15.2 \%$ of the respondents who did not seek medical intervention attributed it to cultural beliefs and other reasons respectively.

3. Another area of major concern is the stigma associated with the disease. This accounted for $35.9 \%$ of the study subjects who did not seek medical attention. It is recommended that intensive education be carried out in the region that direction. This can be effectively executed by targeting the community and opinion leaders who will disseminate the information down to community members. 
South American Journal of Public Health

Volume 4, Issue 2, 2016

4. There is the need for continuous training and capacity building of laboratory staff in $\mathrm{Tb}$ microscopy and quality Assurance to ensure effective diagnosis of TB.

5. Trained and qualified laboratory personnel should be encouraged to accept postings to the district hospitals in order to strengthen laboratory services at the periphery. This encouragement could be in the form of rural incentives as well as career and professional development.

6. The laboratory personnel should be monitored to ensure that they perform routine quality control procedures, and that all Standard Operating Procedures (SOPs) for sputum smear examinations are followed; good maintenance of the TB laboratory register is observed, proper management of reagents and laboratory supplies, good maintenance of microscope, and that they work closely with personnel involved in EQA and Tb control programme.

7. Even though there are a few private health facilities in Tamale and virtually none in those other districts where the study was carried out, those few should be motivated to take up diagnosis of suspected $\mathrm{Tb}$ clients as well as managing and treatment of laboratory confirmed patients. The motivation, aside the free sputum microscopy reagents, slides, containers and grease pencils could be in the form of other reagents such as those of chemistry and haematology such that additional income could be generated for the private service providers.

8. It is important to provide sputum smear microscopy services that are accessible to the entire population, and yet maintain an acceptable level of technical proficiency. To accomplish this objective, a network of laboratories with competency in acid-fast sputum smear microscopy, overseen by a National Tuberculosis Reference Laboratory, is required. The National Tuberculosis Reference Laboratories should support the implementation of QA activities in the regions.

There is also the need for integration of TB with other programs such as malaria and HIV such that in doing monitoring for say malaria, work on TB could be monitored alongside. This is because, running parallel programs has not helped achieve much.

\section{References}

[1] (2005) Tuberculosis bacteriology--priorities and indications in high prevalence countries: position of the technical staff of the Tuberculosis Division of the International Union Against Tuberculosis and Lung Disease. Int J Tuberc Lung Dis 9, 355-361.

[2] Addo K., Owusu-Darko K., Yeboah-Manu D., Caulley P., Minamikawa M., Bonsu F., Leinhardt C., Akpedonu P. and Ofori-Adjei D. (2007) Mycobacterial species causing pulmonary tuberculosis at the korle bu teaching hospital, accra, ghana. Ghana Med J 41, 52-57.

[3] Addo K.K., Dan-Dzide M., Yeboah-Manu D., Owusu-Darko K., Caulley P., Minamikawa M., Bonsu F., Lienhardt C., Akpedonu P. and Ofori-Adjei D. (2006) Improving the laboratory diagnosis of TB in Ghana: the impact of a quality assurance system. Int J Tuberc Lung Dis 10, 812-817.

[4] Adeleye I.A., Onubogu C.C., Ayolabi C.I., Isawumi A.O. and Nshiogu M.E. (2008) Screening of crude extracts of twelve medicinal plants and "wonder-cure" concoction used in Nigeria unorthodox medicine for activity against Mycobacterium tuberculosis isolated from tuberculosis patients' sputum. African Journal of Biotechnology 7, 3182-3187.

[5] Aziz M., Becx-Bleumink B.F., Bretzel G., Humes R. and Iademarco M.F. (2002) External quality assessment for AFB smear microscopy. Washington: Association of Public Health Laboratories.

[6] Aziz M. and Bretzel G. (2002) Use of a standardised checklist to assess peripheral sputum smear microscopy laboratories for tuberculosis diagnosis in Uganda. Int J Tuberc Lung Dis 6, 340-349.

[7] Aziz M.A., Rysweska K., Laszlo A. and Blanc L. (2006) Strategic approach for the strengthening of laboratory services for tuberculosis control, 2006-2009. Geneva: WHO.

[8] Baghdadi J.E., Orlova M., Alter A., Ranque B., Chentoufi M., Lazrak F., Archane M.I., Casanova J.L., Benslimane A., Schurr E. and Abel L. (2006) An autosomal dominant major gene confers predisposition to pulmonary tuberculosis in adults. J Exp Med 203, 1679-1684. 


\section{South American Journal of Public Health}

Volume 4, Issue 2, 2016

[9] Banerji D. and Andersen S. (1963) A Sociological Study of Awareness of Symptoms among Persons with Pulmonary Tuberculosis. Bull World Health Organ 29, 665-683.

[10] Barnes D.S. (1995) The Making of a Social Disease: Tuberculosis in Nineteenth-century France. . University of California Press.

[11] Bass J.B., Jr. (1989) The face of TB changes again. Hosp Pract (Off Ed) 24, 81-85, 88, 93-85, passim.

[12] Becker M.H. (1985) Patient adherence to prescribed therapies. Med Care 23, 539-555.

[13] Blaak E. (2001) Gender differences in fat metabolism. Curr Opin Clin Nutr Metab Care 4, 499-502.

[14] Bonah C. (2005) The 'experimental stable' of the BCG vaccine: safety, efficacy, proof, and standards, 1921-1933. Stud Hist Philos Biol Biomed Sci 36, 696-721.

[15] Borgdorff M.W., Nagelkerke N.J., Dye C. and Nunn P. (2000) Gender and tuberculosis: a comparison of prevalence surveys with notification data to explore sex differences in case detection. Int $J$ Tuberc Lung Dis 4, 123-132.

[16] Bustamante J., Picard C., Fieschi C., Filipe-Santos O., Feinberg J., Perronne C., Chapgier A., de Beaucoudrey L., Vogt G., Sanlaville D., Lemainque A., Emile J.F., Abel L. and Casanova J.L. (2007) A novel X-linked recessive form of Mendelian susceptibility to mycobaterial disease. J Med Genet 44, e65. [17] Calippe B., Douin-Echinard V., Laffargue M., Laurell H., Rana-Poussine V., Pipy B., Guery J.C., Bayard F., Arnal J.F. and Gourdy P. (2008) Chronic estradiol administration in vivo promotes the proinflammatory response of macrophages to TLR4 activation: involvement of the phosphatidylinositol 3-kinase pathway. J Immunol 180, 7980-7988.

[18] Chrisman N. and Kleinman A. (1983) Popular health care, social networks, and cultural meanings: the orientation of medical anthropology. In Handbook of health, health care, and the health professions,, pp. 569-590 [D. Mechanic, editor]. New York: The Free Press.

[19] Comstock G.W. (1994) The International Tuberculosis Campaign: a pioneering venture in mass vaccination and research. Clin Infect Dis 19, 528-540.

[20] Curry F.J. (1968) Neighborhood clinica for more effective outpatient treatment of tuberculosis. $N$ Engl J Med 279, 1262-1267.

[21] Daniel T.M. (1982) Selective primary health care: strategies for control of disease in the developing world. II. Tuberculosis. Rev Infect Dis 4, 1254-1265.

[22] Daniel T.M. (2004) The impact of tuberculosis on civilization. Infect Dis Clin North Am 18, 157-165.

[23] Davila S., Hibberd M.L., Hari Dass R., Wong H.E., Sahiratmadja E., Bonnard C., Alisjahbana B., Szeszko J.S., Balabanova Y., Drobniewski F., van Crevel R., van de Vosse E., Nejentsev S., Ottenhoff T.H. and Seielstad M. (2008) Genetic association and expression studies indicate a role of toll-like receptor 8 in pulmonary tuberculosis. PLoS Genet 4, e1000218.

[24] Deuschle K. and Adair J. (1960) An interdisciplinary approach to public health on the Navajo Indian reservation: medical and anthropological aspects. Ann NY Acad Sci 17, 887-905.

[25] Drobniewski F.A., Caws M., Gibson A. and Young D. (2003) Modern laboratory diagnosis of tuberculosis. Lancet Infect Dis 3, 141-147.

[26] Drobniewski F.A., Hoffner S., Rusch-Gerdes S., Skenders G. and Thomsen V. (2006) Recommended standards for modern tuberculosis laboratory services in Europe. Eur Respir J 28, 903-909.

[27] Dubos R.J. and Jean D. (1987) The White Plague: Tuberculosis, Man, and Society. Rutgers University Press.

[28] Ebara R.V.B., Madunagu E.U. and Otung I.N. (1990) Microbiological exploitation of Cardiac Glycosides and Alkaloids from Garcinia kola and Borreriaocymoides. J. Bacteriol 871, 398-401.

[29] Fortin A., Abel L., Casanova J.L. and Gros P. (2007) Host genetics of mycobacterial diseases in mice and men: forward genetic studies of BCG-osis and tuberculosis. Annu Rev Genomics Hum Genet 8, 163192.

[30] Fox W. (1983) Compliance of patients and physicians: experience and lessons from tuberculosis-I. Br Med J (Clin Res Ed) 287, 33-35.

[31] Friemodt-Moller J. (1968) Domiciliary drug therapy of pulmonary tuberculosis in a rural population in India. Tubercle 49 (supp.), 22-23.

[32] Gangadharam P.R.J., Reichmann L.B. and Hershfield E.S. (1993) Drug resistance in tuberculosis. In A Comprehensive International Approach, pp. 293-328. [M. Deke, editor]. 
South American Journal of Public Health

Volume 4, Issue 2, 2016

[33] Gordon S. and Rylance J. (2009) Where there's smoke... there's tuberculosis. Thorax 64, 649-650.

[34] Grossman C.J. (1985) Interactions between the gonadal steroids and the immune system. Science 227, 257-261.

[35] Haefner D.P. and Kirscht J.P. (1970) Motivational and behavioral effects of modifying health beliefs. Public Health Rep 85, 478-484.

[36] Hamid Salim M.A., Declercq E., Van Deun A. and Saki K.A. (2004) Gender differences in tuberculosis: a prevalence survey done in Bangladesh. Int J Tuberc Lung Dis 8, 952-957.

[37] Hargreaves N.J., Kadzakumanja O., Whitty C.J., Salaniponi F.M., Harries A.D. and Squire S.B. (2001) 'Smear-negative' pulmonary tuberculosis in a DOTS programme: poor outcomes in an area of high HIV seroprevalence. Int J Tuberc Lung Dis 5, 847-854.

[38] Hawken M.P., Muhindi D.W., Chakaya J.M., Bhatt S.M., Ng'ang'a L.W. and Porter J.D. (2001) Under-diagnosis of smear-positive pulmonary tuberculosis in Nairobi, Kenya. Int J Tuberc Lung Dis 5, 360-363.

[39] Herrera M., Senties R., Esquivel E. and Armas J. (1971) [Social problems of the tuberculosis patient in long term care hospitals]. Salud Publica Mex 13, 749-762.

[40] Hill A.V. (2006) Aspects of genetic susceptibility to human infectious diseases. Annu Rev Genet 40, 469-486.

[41] Hochbaum G.M. (1956) Why people seek diagnostic x-rays. Public Health Rep 71, 377-380.

[42] Holmes C.B., Hausler H. and Nunn P. (1998) A review of sex differences in the epidemiology of tuberculosis. Int J Tuberc Lung Dis 2, 96-104.

[43] Hunt L.M., Jordan B., Irwin S. and Browner C.H. (1989) Compliance and the patient's perspective: controlling symptoms in everyday life. Cult Med Psychiatry 13, 315-334.

[44] Janele D., Lang T., Capellino S., Cutolo M., Da Silva J.A. and Straub R.H. (2006) Effects of testosterone, 17beta-estradiol, and downstream estrogens on cytokine secretion from human leukocytes in the presence and absence of cortisol. Ann N Y Acad Sci 1069, 168-182.

[45] Janz N.K. and Becker M.H. (1984) The Health Belief Model: a decade later. Health Educ Q 11, 147.

[46] Jasmer R.M., Roemer M., Hamilton J., Bunter J., Braden C.R., Shinnick T.M. and Desmond E.P. (2002) A prospective, multicenter study of laboratory cross-contamination of Mycobacterium tuberculosis cultures. Emerg Infect Dis 8, 1260-1263.

[47] Kendall C. and Thoits P. The impact of culture on the cognitive structure of illness. Cult Med Psychiatry 11, 465-494.

[48] Khan M.S., Dar O., Sismanidis C., Shah K. and Godfrey-Faussett P. (2007) Improvement of tuberculosis case detection and reduction of discrepancies between men and women by simple sputumsubmission instructions: a pragmatic randomised controlled trial. Lancet 369, 1955-1960.

[49] Kochi A. (1991) The global tuberculosis situation and the new control strategy of the World Health Organization. Tubercle 72, 1-6.

[50] Kopanoff D.E., Snider D.E., Jr. and Johnson M. (1988) Recurrent tuberculosis: why do patients develop disease again? A United States Public Health Service cooperative survey. Am J Public Health 78, 30-33.

[51] Kumate J. (1990) Las enfermedadestransmisibles. In Salud y crisis en Mexico, pp. 17-39 [SigloVeintiuno, editor. Mexico City: I. Almada Bay.

[52] Kusznierz G.F., Latini O.A. and Sequeira M.D. (2004) Quality assessment of smear microscopy for acid-fast bacilli in the Argentine tuberculosis laboratory network, 1983-2001. Int J Tuberc Lung Dis 8, 1234-1241.

[53] Laszlo A., Rahman M., Espinal M. and Raviglione M. (2002) Quality assurance programme for drug susceptibility testing of Mycobacterium tuberculosis in the WHO/IUATLD Supranational Reference Laboratory Network: five rounds of proficiency testing, 1994-1998. Int J Tuberc Lung Dis 6, 748-756.

[54] Leff A.R. and Leff D.R. (1986) Tuberculosis: a reflection of political institutions and social concerns in the United States. Perspect Biol Med 30, 27-39.

[55] Leone M., Honstettre A., Lepidi H., Capo C., Bayard F., Raoult D. and Mege J.L. (2004) Effect of sex on Coxiella burnetii infection: protective role of 17beta-estradiol. J Infect Dis 189, 339-345. 
[56] Lieban R.W. (1976) Traditional medical beliefs and the choice of practitioners in a Philippine city. Soc Sci Med 10, 289-296.

[57] Lienhardt C., Fielding K., Sillah J.S., Bah B., Gustafson P., Warndorff D., Palayew M., Lisse I., Donkor S., Diallo S., Manneh K., Adegbola R., Aaby P., Bah-Sow O., Bennett S. and McAdam K. (2005) Investigation of the risk factors for tuberculosis: a case-control study in three countries in West Africa. Int J Epidemiol 34, 914-923.

[58] Lin C.M., Davidson T.M. and Ancoli-Israel S. (2008) Gender differences in obstructive sleep apnea and treatment implications. Sleep Med Rev 12, 481-496.

[59] Liu P.T., Stenger S., Li H., Wenzel L., Tan B.H., Krutzik S.R., Ochoa M.T., Schauber J., Wu K., Meinken C., Kamen D.L., Wagner M., Bals R., Steinmeyer A., Zugel U., Gallo R.L., Eisenberg D., Hewison M., Hollis B.W., Adams J.S., Bloom B.R. and Modlin R.L. (2006) Toll-like receptor triggering of a vitamin D-mediated human antimicrobial response. Science 311, 1770-1773.

[60] Marriott I. and Huet-Hudson Y.M. (2006) Sexual dimorphism in innate immune responses to infectious organisms. Immunol Res 34, 177-192.

[61] Martin R., Hearn T.L., Ridderhof J.C. and Demby A. (2005) Implementation of a quality systems approach for laboratory practice in resource-constrained countries. AIDS 19 Suppl 2, S59-65.

[62] Martinez A., Balandrano S., Parissi A., Zuniga A., Sanchez M., Ridderhof J., Lipman H.B. and Madison B. (2005) Evaluation of new external quality assessment guidelines involving random blinded rechecking of acid-fast bacilli smears in a pilot project setting in Mexico. Int J Tuberc Lung Dis 9, 301305.

[63] Mata J.I. (1985) Integrating the client's perspective in planning a tuberculosis education and treatment program in Honduras. Med Anthropol 9, 57-64.

[64] Maulitz R.C. and Maulitz S.R. (1973) The King's Evil in Oxfordshire. Med Hist 17, 87-89.

[65] McCarthy O.R. (2001) The key to the sanatoria. J R Soc Med 94, 413-417.

[66] McClelland C. (1909) "Galen on Tuberculosis".The Physician and Surgeon. Detroit and Ann Arbor: Keating and Bryant 31, 400-404.

[67] Miller E.N., Jamieson S.E., Joberty C., Fakiola M., Hudson D., Peacock C.S., Cordell H.J., Shaw M.A., Lins-Lainson Z., Shaw J.J., Ramos F., Silveira F. and Blackwell J.M. (2004) Genome-wide scans for leprosy and tuberculosis susceptibility genes in Brazilians. Genes Immun 5, 63-67.

[68] Moysen J.S. and Arroyo Acevedo P. (1984) Critica de la validez de los metodos de deteccion y confirmacion de la tuberculosis pulmonarcomo un problema de saludpublica. SaludPublica de Mexico 26, 546-555.

[69] Mundy C.J., Harries A.D., Banerjee A., Salaniponi F.M., Gilks C.F. and Squire S.B. (2002) Quality assessment of sputum transportation, smear preparation and AFB microscopy in a rural district in Malawi. Int $J$ Tuberc Lung Dis 6, 47-54.

[70] Munyati S.S., Dhoba T., Makanza E.D., Mungofa S., Wellington M., Mutsvangwa J., Gwanzura L., Hakim J., Nyakabau M., Mason P.R., Robertson V., Rusakaniko S., Butterworth A.E. and Corbett E.L. (2005) Chronic cough in primary health care attendees, Harare, Zimbabwe: diagnosis and impact of HIV infection. Clin Infect Dis 40, 1818-1827.

[71] Nashold F.E., Spach K.M., Spanier J.A. and Hayes C.E. (2009) Estrogen controls vitamin D3mediated resistance to experimental autoimmune encephalomyelitis by controlling vitamin D3 metabolism and receptor expression. J Immunol 183, 3672-3681.

[72] Ober C., Loisel D.A. and Gilad Y. (2008) Sex-specific genetic architecture of human disease. Nat Rev Genet 9, 911-922.

[73] Pamra S.P. (1980) Problems of tuberculosis in developing countries. Clin Chest Med 1, 265-271.

[74] Perkins M.D., Roscigno G. and Zumla A. (2006) Progress towards improved tuberculosis diagnostics for developing countries. Lancet 367, 942-943.

[75] Petti C.A., Polage C.R., Quinn T.C., Ronald A.R. and Sande M.A. (2006) Laboratory medicine in Africa: a barrier to effective health care. Clin Infect Dis 42, 377-382.

[76] Pitchenik A.E. (1984) Monitoring compliance with anti-tuberculosis therapy. $N$ Engl J Med 311, 799. 
South American Journal of Public Health

Volume 4, Issue 2, 2016

[77] Ridderhof J.C., Williams L.O., Legois S., Shult P.A., Metchock B., Kubista L.N., Handsfield J.H., Fehd R.J. and Robinson P.H. (2003) Assessment of laboratory performance of nucleic acid amplification tests for detection of Mycobacterium tuberculosis. J Clin Microbiol 41, 5258-5261.

[78] Rieder H.L., Arnadottir T., Tardencilla Gutierrez A.A., Kasalika A.C., Salaniponi F.L., Ba F., Diop A.H., Anagonou S., Gninafon M., Ringdal T., Trebucq A. and Enarson D.A. (1997) Evaluation of a standardized recording tool for sputum smear microscopy for acid-fast bacilli under routine conditions in low income countries. Int J Tuberc Lung Dis 1, 339-345.

[79] Roberts C.W., Walker W. and Alexander J. (2001) Sex-associated hormones and immunity to protozoan parasites. Clin Microbiol Rev 14, 476-488.

[80] Roden A.C., Moser M.T., Tri S.D., Mercader M., Kuntz S.M., Dong H., Hurwitz A.A., McKean D.J., Celis E., Leibovich B.C., Allison J.P. and Kwon E.D. (2004) Augmentation of T cell levels and responses induced by androgen deprivation. J Immunol 173, 6098-6108.

[81] Rosenstock I.M. (1974) Historical origins of the health belief model. In The health belief model and personal health behavior, pp. 1-8 [M.H. Becker and C.B. Slack, editors]. Thorofare, NJ.

[82] Rubel A.J. and Garro L.C. (1992) Social and cultural factors in the successful control of tuberculosis. Public Health Rep 107, 626-636.

[83] Rubel A.J. and O'Nell C.W. (1978) Difficulties of presenting complaints to physicians: susto illness as an example. In Modern medicine and medical anthropology in the United States-Mexico border population, pp. 147-154 [B. Velimirovic, editor]. Washington, DC: Pan American Health Organization.

[84] Ryan K.J. and Ray C.G. (2004) Sherris Medical Microbiology.

[85] San Antonio-Gaddy M., Richardson-Moore A., Burstein G.R., Newman D.R., Branson B.M. and Birkhead G.S. (2006) Rapid HIV antibody testing in the New York State Anonymous HIV Counseling and Testing Program: experience from the field. J Acquir Immune Defic Syndr 43, 446-450.

[86] Schaible U.E., Collins H.L., Priem F. and Kaufmann S.H. (2002) Correction of the iron overload defect in beta-2-microglobulin knockout mice by lactoferrin abolishes their increased susceptibility to tuberculosis. J Exp Med 196, 1507-1513.

[87] Shinnick T.M., Lademarco M. and Ridderhof J.C. (2005) National Plan for Reliable Tuberculosis Laboratory Services Using a Systems Approach: Recommendations from CDC and the Association of Public Health Laboratories Task Force on Tuberculosis Laboratory Services. MMWR Morb Mortal Wkly Rep 541, 12.

[88] Slutkin G. (1986) Management of tuberculosis in urban homeless indigents. Public Health Rep 101, 481-485.

[89] Small P.M., McClenny N.B., Singh S.P., Schoolnik G.K., Tompkins L.S. and Mickelsen P.A. (1993) Molecular strain typing of Mycobacterium tuberculosis to confirm cross-contamination in the mycobacteriology laboratory and modification of procedures to minimize occurrence of false-positive cultures. J Clin Microbiol 31, 1677-1682.

[90] Styblo K. (1989) Overview and epidemiologic assessment of the current global tuberculosis situation with an emphasis on control in developing countries. Rev Infect Dis 11 Suppl 2, S339-346.

[91] Sudre N., ten Dam G. and Kochi A. (1991) Tuberculosis in the present time: a global overview of the tuberculosis situation. Geneva: World Health Organization.

[92] Tsuyuguchi K., Suzuki K., Matsumoto H., Tanaka E., Amitani R. and Kuze F. (2001) Effect of oestrogen on Mycobacterium avium complex pulmonary infection in mice. Clin Exp Immunol 123, 428434.

[93] Tuberculosis Research Centre M., and National Tuberculosis Institute, Bangalore (1984) A controlled clinical trial of 3- and 5-month regimes in the treatment of sputum positive pulmonary tuberculosis. Ann Rev Respir Dis 130, 1091-1094.

[94] Van Deun A., Kim S.J. and Rieder H.L. (2005) Will the bleach method keep its promise in sputum smear microscopy? Int J Tuberc Lung Dis 9, 700; author reply 700-701.

[95] Van Deun A. and Portaels F. (1998) Limitations and requirements for quality control of sputum smear microscopy for acid-fast bacilli. Int J Tuberc Lung Dis 2, 756-765.

[96] Vidal S.M., Malo D., Vogan K., Skamene E. and Gros P. (1993) Natural resistance to infection with intracellular parasites: isolation of a candidate for Bcg. Cell 73, 469-485. 


\section{South American Journal of Public Health}

Volume 4, Issue 2, 2016

[97] Weiss M.G., Sommerfeld J. and Uplekar M.W. (2008) Social and cultural dimensions of gender and tuberculosis. Int J Tuberc Lung Dis 12, 829-830.

[98] WHO (1998a) Laboratory services in TB control, Part I: Organization and management. Geneva: World Health Organization.

[99] WHO (1998b) Laboratory services in TB control, Part II: Microscopy. Geneva: World Health Organization.

[100] WHO (1998c) Laboratory services in TB control. Part III: Culture. Geneva: World Health Organization.

[101] WHO (1998d) Laboratory services in tuberculosis control; part I: organization and management. Geneva.

[102] WHO (2004) The WHO/IUATLD Global Project on Anti-Tuberculosis Drug Resistance Surveillance. Anti-tuberculosis drug resistance in the world. Geneva: WHO.

[103] WHO (2005) Global Tuberculosis Control Report: World Health Organization.

[104] WHO (2006) The Stop TB Strategy. Geneva.

[105] WHO (2007) Use of Liquid TB Culture and Drug Susceptibility Testing in Low- and Mediumincome Settings: World Health Organization.

[106] WHO (2008a) Policy Guidance on Drug Susceptibility Testing (DST) of Second-line AntiTuberculosis Drugs. Geneva: World Health Organization.

[107] WHO (2008b) Policy Statement. Molecular Line Probe Assay for Rapid Screening of Patients at Risk of Multidrug-resistant (MDR) TB. Geneva: World Health Organization.

[108] WHO (2010a) Policy Statement on Fluorescent Light Emitting Diode Microscopy for Diagnosis of Tuberculosis: World Health Organization.

[109] WHO (2010b) Policy Statement on Non-commercial Culture and DST Methods for rapid screening of Patients at Risk of Multidrug-resistant Tuberculosis. Geneva: World Health Organization.

[110] WHO (2011a) Intensifying TB case detection in Ghana.

[111] WHO (2011b) Policy Statement Automated real-time nucleic acid amplification technology for rapid and simultaneous detection of tuberculosis and rifampicin resistance: Xpert MTB/RIF system Geneva: World Health Organization.

[112] Wolfart W. (1990) Surgical treatment of tuberculosis and its modifications — collapse therapy and resection treatment and their present-day sequelae. OffentlGesundheitswes 52, 506-511.

[113] Yamamoto Y., Saito H., Setogawa T. and Tomioka H. (1991) Sex differences in host resistance to Mycobacterium marinum infection in mice. Infect Immun 59, 4089-4096.

[114] Yamamoto Y., Tomioka H., Sato K., Saito H., Yamada Y. and Setogawa T. (1990) Sex differences in the susceptibility of mice to infection induced by Mycobacterium intracellulare. Am Rev Respir Dis 142, 430-433.

[115] Young J.C. and Garro L.Y. (1982) Variation in the choice of treatment in two Mexican communities. Soc Sci Med 16, 1453-1465.

[116] Zimmermann M.B. and Hurrell R.F. (2007) Nutritional iron deficiency. Lancet 370, 511-520.

[117] Zink A.R., Sola C., Reischl U., Grabner W., Rastogi N., Wolf H. and Nerlich A.G. (2003) Characterization of Mycobacterium tuberculosis complex DNAs from Egyptian mummies by spoligotyping. J Clin Microbiol 41, 359-367. 